Max-Planck-Institut für demografische Forschung

Max Planck Institute for Demographic Research

Konrad-Zuse-Strasse 1 - D-18057 Rostock - Germany - Tel +49 (0) 3812081 - 0 - Fax +49 (0) 3812081 - 202 - www.demogr.mpg.de

MPIDR Working Paper WP 2019-018 I September 2019

\title{
Educational differences in cohort fertility across sub-national regions in Europe
}

\author{
Jessica Nisén I nisen@demogr.mpg.de \\ Sebastian Klüsener \\ Johan Dahlberg \\ Lars Dommermuth \\ Aiva Jasilioniene I jasilioniene@demogr.mpg.de \\ Michaela Kreyenfeld \\ Trude Lappegård \\ Peng Li I li@demogr.mpg.de \\ Pekka Martikainen \\ Karel Neels \\ Bernhard Riederer \\ Saskia te Riele \\ Laura Szabó \\ Alessandra Trimarchi \\ Francisco Viciana \\ Ben Wilson \\ Mikko Myrskylä I sekmyrskyla@demogr.mpg.de
}

\footnotetext{
This working paper has been approved for release by: Mathias Lerch (lerch@demogr.mpg.de), Deputy Head of the Laboratory of Fertility and Well-Being.

(ㄷ) Copyright is held by the authors.
} 


\section{Educational differences in cohort fertility across sub-national regions in Europe}

Jessica Nisén ${ }^{1}$, Sebastian Klüsener ${ }^{1,2,3}$, Johan Dahlberg ${ }^{4}$, Lars Dommermuth ${ }^{5}$, Aiva Jasilioniene ${ }^{1}$, Michaela Kreyenfeld ${ }^{6}$, Trude Lappegård ${ }^{7}$, Peng Li $^{1}$, Pekka Martikainen ${ }^{1,8}$, Karel Neels ${ }^{9}$, Bernhard Riederer $^{10,11}$, Saskia te Riele ${ }^{12}$, Laura Szabó ${ }^{13}$, Alessandra Trimarchi ${ }^{14}$, Francisco Viciana ${ }^{15}$, Ben Wilson ${ }^{4}$, Mikko Myrskylä ${ }^{1,8,16}$

${ }^{1}$ Max Planck Institute for Demographic Research (Germany)

${ }^{2}$ Federal Institute for Population Research (Germany)

${ }^{3}$ Vytautas Magnus University (Lithuania)

${ }^{4}$ Stockholm University (Sweden)

${ }^{5}$ Statistics Norway (Norway)

${ }^{6}$ Hertie School of Governance (Germany)

${ }^{7}$ University of Oslo (Norway)

${ }^{8}$ University of Helsinki (Finland)

${ }^{9}$ University of Antwerp (Belgium)

${ }^{10}$ Vienna Institute of Demography (Austria)

${ }^{11}$ University of Vienna (Austria)

${ }^{12}$ Statistics Netherlands (Netherlands)

${ }^{13}$ Hungarian Demographic Research Institute (Hungary)

${ }^{14}$ Institut National D'études Démographiques (France)

${ }^{15}$ Institute of Statistics and Cartography of Andalusia (Spain)

${ }^{16}$ London School of Economics (United Kingdom)

Educational differences in female cohort fertility have been shown to vary across high-income countries and over time, but knowledge about how educational fertility differentials play out at the sub-national regional level is limited. Examining these sub-national regional patterns might improve our understanding of national patterns, as regionally varying contextual conditions may affect fertility. This study provides for the first time for a large number of European countries a comprehensive account of educational differences in the cohort fertility rate (CFR) at the sub-national regional level. We harmonise data from population registers, censuses, and large-sample surveys for 15 countries in order to measure women's completed fertility by educational level and region of residence at the end of the reproductive lifespan. In order to explore associations between educational differences in CFRs and levels of economic development, we link our data to regional estimates of GDP per capita. Empirical Bayesian estimation is used to reduce uncertainty in the regional fertility estimates. Our results document an overall negative gradient between the CFR and level of education, and notable variation in the gradient across regions. The gradient varies systematically by the level of economic development: moving from less to more developed regions, we observe smaller gradients both across countries and within countries. However, the within-country patterns of countries differ. Our findings underline the variability of educational gradients in women's fertility, suggest that higher levels of development may be associated with less negative gradients, and call for more in-depth fertility analyses by education at the sub-national level. 


\section{Introduction}

Research on variation in fertility in contemporary societies often focuses on the relationship between education and fertility (Gustafsson \& Kalwij, 2006; Kreyenfeld \& Konietzka, 2017; Sobotka, Beaujouan, \& Van Bavel, 2017). There is evidence that the typically negative relationship between education and fertility has varied across place (Beaujouan, Brzozowska, \& Zeman, 2016; Klesment, Puur, Rahnu, \& Sakkeus, 2014; Van Bavel et al., 2018; Wood, Neels, \& Kil, 2014) and time (Andersson et al., 2009; Jalovaara et al., 2019; Kravdal \& Rindfuss, 2008; Neels \& De Wachter, 2010). However, most previous analyses on this relationship have been conducted at the country level, while paying little attention to potential variation in this relationship across regions within countries. National patterns are, however, composites of sub-national regional patterns. As regionally varying contextual conditions may affect fertility outcomes (Basten, Huinink, \& Klüsener, 2012; de Beer \& Deerenberg, 2007; Kulu, 2013), exploring this dimension might improve our understanding of observed national-level patterns in educational gradients in fertility (Snyder, 2001). A perspective beyond the national level also has value in light of globalisation theories predicting that affluent, developed sub-national regions across countries will become more similar to each other over time, even as regional differences in living conditions within countries are increasing (Veltz, 2014).

From a macro perspective, socio-economic development is among the central determinants of fertility levels (Bryant, 2007; Lee, 2003). While in the past countries with higher levels of socio-economic development tended to have lower fertility levels, among contemporary high-income countries, this long-standing negative relationship has reversed (Luci-Greulich \& Thévenon, 2013; Myrskylä, Kohler, \& Billari, 2009). A similar tendency is observed within European countries, as the association of fertility with the level of economic development across sub-national regions has, in recent decades, become less negative, or even positive (Fox, Klüsener, \& Myrskylä, 2019). Our study is motivated by these recent changes. It is possible that changes in the fertility-education relationship at the regional level have contributed to the changing regional patterns of development and fertility, as, for example, the higheducated are particularly concentrated in highly developed areas (Eurostat 2019). Our study aims to make a novel contribution by investigating for the first time for a large number of European countries the educational patterning of cohort fertility rates (CFRs) at the sub-national regional level. We seek to bridge previous studies on the relationships between education and fertility and development and fertility by exploring whether regional variation in CFRs by educational attainment is systematically associated with regional variation in economic development. 
Existing research on educational differences in cohort fertility shows that higher-educated women have had lower CFRs at least since the early $20^{\text {th }}$ century (Skirbekk, 2008). However, in the cohorts born up to the mid-1940s, there was convergence towards a two-child family model across educational groups, which in some countries led to a decrease in the educational gradient in CFR (Van Bavel et al., 2018). Moreover, the gap in childlessness between low- and middle-educated women, which has been an important factor in CFR differentials, declined among the mid- $20^{\text {th }}$-century cohorts (Beaujouan et al., 2016). Further deviations from the well-known pattern of a negative educational gradient in CFRs have been reported for female cohorts born between the 1940s and the mid-1970s in Northern and NorthWestern Europe, where gradients have narrowed, and are often no longer observable (Andersson et al., 2009; Jalovaara et al., 2019; Kravdal \& Rindfuss, 2008; Neels \& De Wachter, 2010). So far, however, there has been no overall convergence in cohort fertility among educational groups across high-income countries (Sobotka, Beaujouan, \& Brzozowska, 2018), and the magnitude of fertility gradients continues to vary greatly across countries (Beaujouan et al., 2016; Klesment et al., 2014; Neyer \& Hoem, 2008; Wood et al., 2014).

Women's cohort fertility results from consecutive decisions and events in the life course that are shaped by contextual factors (Huinink \& Kohli, 2014; Thomson, Winkler-Dworak, \& Kennedy, 2013). Thus, at the sub-national level, cohort fertility is subject to regional contextual conditions across the reproductive lifespan (Kulu, 2013; Kulu, Vikat, \& Andersson, 2007). As we will discuss in this section, regionally-varying contextual conditions might affect childbearing opportunity structures differently depending on women's educational levels, and can lead to variation between regions in the educational gradient in fertility. For example, while high regional living costs due to factors like expensive housing are likely to depress childbearing by contributing to high direct costs of children (Dettling \& Kearney, 2014; Flynn, 2017; Mulder, 2013), the childbearing of high-educated women might be less sensitive to such mechanisms because they are more likely to have high household income levels (Esping-Andersen, 2009; Konietzka \& Kreyenfeld, 2010). Employment has recently become an important prerequisite for childbearing in most European countries (Matysiak \& Vignoli, 2008), particularly among high-educated women (Kreyenfeld \& Andersson, 2014; Wood \& Neels, 2017). We can therefore hypothesise that regional employment prospects (Bujard \& Scheller, 2017; Kravdal, 2002) are particularly important for these women. Furthermore, the availability of flexible working arrangements that support work-family reconciliation, such as working remotely from home, is likely to vary regionally (Fox et al., 2019), and might be more prevalent among high-educated employees (Golden, 2001). The positive effect on fertility of the regional availability of childcare services (Rindfuss, Guilkey, Morgan, \& 
Kravdal, 2010) has been shown to be particularly strong for high-educated women, most likely because of the high opportunity costs they face when having children (Wood, Klüsener, Neels, \& Myrskylä, 2017).

We can therefore hypothesise that higher living costs, better employment opportunities, and better access to flexible work arrangements and childcare services are among the factors that could lead to relatively high fertility among high-educated women - and, thus, to a less negative regional educational gradient in fertility. Moreover, these contextual factors could bring about systematic variation in the educational gradient depending on the regional level of economic development, given their association with the latter (Dunford, 1996; Fox et al., 2019; Kosfeld, Eckey, \& Lauridsen, 2007; Kurre, 2003). Living costs, employment rates, and access to flexible working practices are typically higher in more developed regions. If higher living costs have fewer negative effects and good employment prospects and access to flexible work arrangements have more positive effects on childbearing among the high-educated, these factors may contribute to less negative educational gradients within more developed regions. It is also plausible that higher concentrations of the high-educated (Eurostat, 2019) and dual-earner couples (de Meester \& Van Ham, 2009) in more developed regions contribute to more demand for and better availability of childcare services in these regions, which could in turn lead to a less negative regional educational gradient. Obviously, in addition to living costs, employment rates, and access to services, normative and cultural factors (Kulu, 2013; Mulder, 2013) may be relevant in this context. Thus, alternative hypotheses might also help to explain regional variation in fertility by educational attainment. ${ }^{1}$

This study aims to describe the educational gradient of the female cohort fertility rate (CFR) at the regional level in contemporary Europe. We assess 1 ) whether there is sub-national regional variation in the educational gradient in CFRs; and 2) whether this variation is systematic by regional level of development. Based on our theoretical considerations, we expect to find that negative educational fertility gradients are more common among women living in less economically developed regions, and that these gradients might be low or even positive in more developed regions. This study investigates the cohort fertility of women born in the late 1960s and early 1970s in 15 European countries. These cohorts are of interest because they recently completed their childbearing, and because in some European countries, their educational gradients in fertility have undergone marked changes. For these

\footnotetext{
${ }^{1}$ For instance, in developed regions, labour markets may also provide more opportunities and be more competitive, both of which could depress fertility, particularly among the high-educated (Kulu, 2013; Kulu \& Washbrook, 2014).
} 
women, we are able to measure number of children, level of education, and region of residence at the end of the reproductive career.

Women may move across regions over their life course - before, during, and after having (any) children. While sub-national migration and family formation are often closely interrelated life course steps, longdistance moves are less common at higher parities and higher reproductive ages (Dommermuth \& Klüsener, 2019; Kulu, 2008; Michielin, 2004). The higher-educated have a greater propensity to migrate, and their reasons for migration are often related to further education and employment. Thus, they typically move to economically developed regions and cities (Berry \& Glaeser, 2005). This pattern likely contributes to higher concentrations of the high-educated in the more developed regions. ${ }^{2}$ For the loweducated, family-related reasons, such as proximity to kin, are more relevant for moving decisions. Thus, their moves seem to be less dependent on the economic development level of the destination region (Dawkins, 2006; Thomas, 2019). Taken together, a woman's region of residence at the end of her reproductive life, as measured in this study, may differ from the region where she lived during her prime childbearing years, possibly even in systematic ways. This can bias attempts to investigate hypothesised effects of regional contextual factors on our measured fertility outcomes. The aim of this study is, therefore, not to validate a causal link between contextual factors and fertility, but to describe educational patterning of cohort fertility among women by the region of residence at the end of the reproductive lifespan.

\section{Data and methods}

The datasets utilised in this study are described in Table 1. The study is based on register, census, and large-scale survey data. We cover 15 countries: Austria, Belarus, Belgium, Finland, France, Germany, Greece, Hungary, Ireland, Lithuania, the Netherlands, Norway, Romania, Spain, and Sweden. The study analyses native-born women born between 1964 and 1970. Cohort fertility, highest educational attainment, region of residence, and level of economic development are measured at the end of the reproductive career. In most countries, the data reflect the achieved fertility as of 2011. All women were aged 40 or older at the time of the measurement.

\footnotetext{
${ }^{2}$ Across Europe in $2018,49 \%$ of women aged $30-34$ had tertiary education and $15 \%$ had primary education; while in the capital regions, the respective shares were $58 \%$ and $13 \%$ (Eurostat, 2019). In the cohorts under study, the educational levels were generally lower.
} 


\section{[TABLE 1 ABOUT HERE]}

The regional classification is based on the Nomenclature of Territorial Units for Statistics (NUTS) classification by Eurostat (Eurostat, 2011), a sub-regional categorisation of territorial units in the European Union. For most countries, we use the NUTS 2 level of classification, which covers regions and smaller countries with between 800,000 and three million inhabitants. Appendix 1 provides detailed information on the regional categorisation.

In register data, information on the region of residence is derived from registers on the place of dwelling. In survey data, it is self-reported. In census data, it is either self-reported or obtained from registers and corrected, where necessary, based on self-reports. We measure regional development using GDP (purchasing power standardised gross domestic product per capita) in 2011 extracted from the Eurostat database (Eurostat, 2018). We also considered other development measures, such as employee compensation, which focuses on household income. But as employee compensation is highly correlated with GDP across European regions and is not available for all regions in our dataset, we decided to use GDP. ${ }^{3}$ See Appendix 2 for GDP per capita across regions.

The measurement of education is based on registers in the register data and self-reports in other data. We distinguish between low, medium, and high educational attainment following the International Standard Classification of Education (ISCED) (UNESCO, 1999). High refers to education at the tertiary level (ISCED 1997 levels 5-6), including short-cycle tertiary level education. Medium refers to education at the higher secondary or post-secondary non-tertiary level (ISCED 1997 levels 3-4). Low refers to

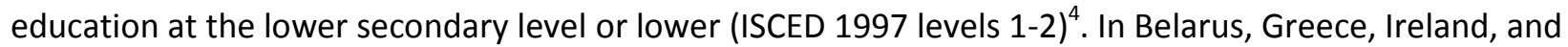
Romania, the classification is based on the standards used by IPUMS international (IPUMS, 2018). ${ }^{5}$ See Appendix 2 for the distribution of the educational attainment by region.

Fertility is measured as the mean total number of children per woman, corresponding to the cohort fertility rate. This number includes all children women have ever given birth to, and is derived from selfreports in census or survey data and information on registered births in register data. In France, the

\footnotetext{
${ }^{3}$ Based on own calculations of the European Regional Dataset (Cambridge Econometrics, 2018), the correlation between GDP per capita and employee compensation was 0.97 across NUTS 2 levels in 2011.

${ }^{4}$ In the Nordic countries, the small shares of women with missing information on educational attainment are classified as low-educated ( $<3 \%$ in Norway, $<1 \%$ in Sweden and Finland).

${ }^{5}$ In order to follow the ISCED as closely as possible, we classify technical education college degrees (Greece), thirdlevel non-degree qualifications (Ireland), and short-term post-secondary (associate) degrees (Romania) as tertiary (see also OECD, 2015).
} 
Netherlands, and Norway, children given for adoption are linked to their adoptive parents instead of their biological parents. The country-specific mean age at the measurement of fertility was at least 42 in all cases except Belgium, where it was 41. Thus, completed fertility is slightly underestimated, particularly in Belgium. Prior research indicates, however, that changes in the educational gradient of women are very small past this age (Andersson et al., 2009; Berrington, Stone, \& Beaujouan, 2015). In census-based data, women reporting unknown parity may cause errors in the parity estimates (Sobotka, 2017). Among the countries in this study for which census or survey data are used, the small numbers of women with unknown parity are redistributed in Belarus, Germany, and Lithuania.

Fertility rates of women by education and region are subject to sampling variation in the 9 out of the 15 countries for which full population data are not available (see Table 1). In order to document variation that reflects true heterogeneity rather than sampling noise, we use a standard method of small area estimation: the empirical Bayesian (EB) estimation (Assunção, Schmertmann, Potter, \& Cavenaghi, 2005; Longford, 1999; Rao, 2014). In this method, statistical power is borrowed from other educational groups and regions in an attempt to limit noise in the fertility rate estimates. We assume that the number of children follows a Poisson distribution, and borrow strength for each educational group (1) from other educational groups within the region, (2) from the same educational groups in other regions within the country, and (3) from regularities in education-specific fertility schedules within the country. Shrinkage of an estimate is stronger when the estimate is based on a smaller sample size and is stronger towards another estimate based on a larger sample size. Additionally, given a correlation between fertility rates and GDP within countries (cross-country mean of correlation coefficient between regional fertility rate and regional logged GDP -0.6), larger weight is given in the estimation to regions that are more similar in terms of their GDP. See Appendix 3 for the details of the method, and Appendixes 4-6 for the comparison between unadjusted CFRs and our preferred EB-adjusted CFRs. Appendixes 9-11 show our main results based on unadjusted CFRs. These findings are stronger than those based on EB adjustment. We consider that the more conservative EB-based results are more likely to reflect reality than the unadjusted measures. 


\section{Results}

\section{A comparison at the country level}

We first situate the sub-national analysis within the broader cross-country context in Europe. National CFRs independent of education range from 1.50 in Germany to 2.09 in Ireland (Table 2). Turning to the CFRs by education, it is relevant to note that the cross-country average of the share of women in each educational category is $32 \%$ for tertiary (range $16-53 \%$ ), $53 \%$ for medium (36-73\%), and $16 \%$ for low (229\%) (Appendix 2). The medium-educated are the largest group in all but two countries (Finland and Norway), while the low-educated are the smallest group in all but one country (Greece). The educational gradient in CFRs is negative in almost all countries, but the magnitude of the gradient varies across countries and educational comparisons. Notably, high- and medium-educated women are, on average, more similar in their CFRs than medium- and low-educated women. The high-educated have, on average, fewer children than the medium-educated in all but one country, with the difference ranging from -0.42 in Romania, to almost zero in Norway and Sweden, to 0.10 in Belgium. The medium-educated have fewer children than the low-educated, with the difference ranging from close to zero in Finland and Norway to -0.68 in Romania and -0.59 in Hungary. In all countries, our derived rates for the higheducated are below those for the low-educated, with the difference ranging from -0.03 (Norway) and 0.01 (Belgium) to -0.69 (Hungary) and -1.10 (Romania).

[TABLE 2 ABOUT HERE]

\section{Variation between and within countries by GDP}

Figure 1 plots for our complete set of regions the CFR difference between the high- and mediumeducated (Figure 1A), the medium- and-low educated (Figure 1B), and the high- and low-educated (Figure 1C) by log-transformed $\mathrm{GDP}^{6}$. The overall pattern that emerges is that of a negative educational gradient that declines as the level of regional economic development increases, and that has considerable variation at any level of GDP. The regions with low GDP tend to display larger educational differences in CFRs. In a number of regions, the difference is reversed; i.e., the high-educated have a higher CFR than the low-educated, particularly among the more developed regions. See Appendix 7 for CFR by education for all regions.

\footnotetext{
${ }^{6}$ See Appendix 2 for within-country variation in educational attainment. In all but four countries (Belgium, Germany, Netherlands, Spain), the share of high-educated women was largest in the region with the highest GDP.
} 
[FIGURE 1A-C ABOUT HERE]

A pattern of the fertility differentials between educational groups becoming smaller as we move from regions with lower GDP to regions with higher GDP is observed both across all countries and within countries. The regression lines superimposed on the graphs show a strong and significant correlation between higher levels of economic development and decreasing differences in fertility between educational groups for all three educational comparisons. Whether this pattern is attributable to variation between or within countries can be tested by regressing the educational fertility difference on GDP while controlling for country fixed effects. The coefficients of these regressions are shown in the bottom-right corner of each of the figures. In each instance, the coefficients suggest that within countries, educational differences in fertility also tend to be smaller as the level of economic development of a region increases. The evidence for the within-country pattern is stronger in the highmedium comparison than in the medium-low comparison. As the figures illustrate, there are exceptions to the general pattern of a smaller gradient, as in some countries the educational fertility gradient is not associated or positively associated with the level of GDP of a region. However, averaged across all countries, the evidence suggests that within countries, a higher level of economic development is also associated with smaller differences in fertility between educational groups. Additional analyses show that countries in Eastern and Central Europe strongly contribute to the within-country pattern; when these countries are excluded, the cross-country association between the educational gradient and GDP persists, but the within-country association becomes flat (Appendix 8).

\section{Regions with the highest GDP and other regions}

In order to better understand within-country patterns, we additionally analyse educational gradients by comparing the economically most developed region to all other regions within each country (Figure 2). There is a general tendency towards smaller educational differences in the most developed regions within countries: in all educational group comparisons, the educational difference averaged across countries is smaller in the region with the highest GDP. However, there is large variation across countries around this average tendency. The three panels shown in Figure 2 indicate that the differences in the magnitudes of the educational gradient between the highest GDP region and other regions are particularly large in Eastern European countries, where the country-level magnitudes of the gradient are also large. In Norway, Sweden, Spain, and Greece, the differences are also smaller in the highest GDP region, but the differences relative to other regions are not as large. In Finland, France, the Netherlands, and Ireland, the differences between the highest GDP region and other regions are small; and in 
Belgium, Austria, and Germany, there are indications that the educational gradient is larger in the highest GDP regions than in other regions.

[FIGURE 2 ABOUT HERE]

\section{Conclusion}

Previous studies have shown that educational differences in women's completed fertility vary between countries and over time. We show that educational gradients also vary across sub-national regions within countries in Europe, and that this variation is notable and quite systematic. Women educated to high and medium levels are, on average, more similar in their completed fertility than women educated to medium and low levels; and the gradient between the high- and low-educated in completed fertility narrows with increasing levels of economic development between and within countries. However, the variation between countries in the within-country pattern is noteworthy. For example, in Hungary, higheducated women have only 0.04 fewer children than medium-educated women in the most developed region, compared to 0.13 fewer children in other areas. Meanwhile, in Belgium, high-educated women have 0.06 fewer children than medium-educated women in the most developed region, but 0.11 more children in other areas.

We expected to find weaker negative gradients in cohort fertility in the more developed regions based on our hypothesis that the contextual conditions in such regions could lead to more similar childbearing patterns among women in different educational groups. For example, the fertility of the low-educated might be particularly depressed in these regions due to higher living costs, while the high-educated might benefit more from better access to employment, childcare services, and flexible work. In line with our expectations, we find that well-developed regions have smaller differentials in fertility by education. In this descriptive analysis, however, we were not able to test the importance of the hypothesised mechanisms. Further studies could validate the role of regional contextual factors for educational gradients in fertility by linking individual-level data to such factors at the time when childbearing decisions are made (see Hank, 2002; Kulu, 2013). The role of sub-national migration over the life course for the educational patterning of cohort fertility at the regional level also requires investigation. Given the sequential nature of childbearing and the evidence that cohort fertility masks parity-specific variation (Zeman, Beaujouan, Brzozowska, \& Sobotka, 2018), parity-specific analysis (see Fiori, Graham, 
\& Feng, 2014; Kulu \& Washbrook, 2014) may help to disentangle the mechanisms behind the observed patterns.

The environment women born in the late 1960s experienced during their prime childbearing years differed substantially across countries. An elaborated analysis of such between-country differences is beyond our focus, but we note that women in the former communist countries - Belarus, former East Germany (classified here as part of Germany ${ }^{7}$ ), Hungary, Lithuania, and Romania - experienced a very particular childbearing context (Billingsley, 2010; Sobotka, 2011). The female cohorts of the late 1960s were in their early twenties at the onset of the crisis of the Soviet Union in 1989. By then, many of those who had not entered university had already become mothers, while many of those who were students finished their education after the onset of the crisis, and were thus more likely to postpone childbearing. These circumstances contributed to strong variation in fertility in the cohorts studied (Kreyenfeld, 2006). The timing of the crisis may have also contributed to some of the strong regional patterns we observe in the Central and Eastern European countries. Moreover, the high levels of regional inequality in these countries (Petrakos, 2001) may have further contributed to regional variation in educational gradients.

Our data sources vary by country. Measurement is likely to be more accurate in register than in census or survey data. Quality assessment of the small-sample data sources used in the study in Austria (Neuwirth, 2015; Statistics Austria, 2018; Verwiebe, Troger, \& Riederer, 2014), France (INSEE, 2013, 2014), and Germany (Federal Statistical Office and Statistical Offices of the Federal States, 2018) showed relatively high overall response rates (78-95\%), but lower rates among the low-educated and varying rates by region, with the rates being lower in capital regions. We cannot rule out the possibility that measurement error affected the results of this study, but it is unlikely that it would have led to the main results, because the error would need to be differently selective by educational attainment across regions. We were also unable to assess the sensitivity of our results to regional categorisation ("modifiable areal unit problem") (Openshaw, 1984). Given the changes observed over time in educational gradients at the country level, as well as the changes in the association between the level of development and fertility at the sub-national regional level, future studies should investigate whether the regional patterning of educational gradients is subject to change over time by including a wider selection of birth cohorts.

\footnotetext{
${ }^{7}$ The following regions belonged to the German Democratic Republic until 1990: Berlin and Brandenburg, Saxony and Thuringia, and Mecklenburg-Western Pomerania and Saxony-Anhalt.
} 
This study underlines the variability of the educational gradient in fertility. We document an overall negative gradient between CFRs and level of education, and notable variation in the magnitude of the gradient across sub-national regions. While smaller negative gradients are generally found in more economically developed regions, notable differences can be observed between countries in the withincountry patterning of the gradient. The high fertility of high-educated women relative to medium- (or low-) educated women in more developed regions suggests that in Europe, negative educational gradients in cohort fertility at the country level are more strongly driven by women living in less economically prosperous sub-national regions (at the end of their reproductive careers). Furthermore, given that the shares of women with high educational attainment are particularly large in welldeveloped regions, these findings may help to explain why overall fertility has been relatively high in these European regions in recent years. To conclude, this study suggests that using a sub-national regional approach can advance our understanding of the dynamics of educational differentials in fertility, and that more in-depth (comparative) fertility analyses are needed on the relationship between education and fertility at the level of sub-national regions.

Additional material: an interactive map showing women's cohort fertility rate by level of education at the sub-national regional level in 15 European countries: https://fertility.shinyapps.io/cfr edu region/; the cohort fertility rates in digital format and the code used to generate the interactive map: https://github.com/DemogrFertility/cfr edu region.

Funding and acknowledgements: The contribution of Trude Lappegård and Lars Dommermuth to this work was supported by the Norwegian Research Council (Grant Nr. 236926/H20 and 287634). Aiva Jasilioniene and Sebastian Klüsener were supported by the Research Council of Lithuania (Grant Nr. SMIP-17-119). Alessandra Trimarchi was supported by the French National Research Agency (Grant Nr. ANR-16-CE41-0007-01). Mikko Myrskylä was supported by the European Research Council Grant 336475 (COSTPOST). The authors wish to acknowledge in particular the following statistical offices that provided the underlying data that made this research possible: Ministry of Statistics and Analysis, Belarus; National Institute of Statistics, Romania; National Statistical Office, Greece; Central Statistics Office, Ireland; Statistics Finland, permission TK53-780-11. We thank Harun Sulak for providing the data for Germany. We thank Gunnar Andersson, Mathias Lerch, and other members of the Register-Based Fertility Research Network for their helpful comments. 


\section{References}

Andersson, G., Rønsen, M., Knudsen, L. B., Lappegård, T., Neyer, G., Skrede, K., . . Vikat, A. (2009). Cohort Fertility Patterns in the Nordic Countries. Demographic Research, 20(14), 313-352.

Assunção, R. M., Schmertmann, C. P., Potter, J. E., \& Cavenaghi, S. M. (2005). Empirical Bayes estimation of demographic schedules for small areas. Demography, 42(3), 537-558.

Basten, S., Huinink, J., \& Klüsener, S. (2012). Spatial variation of sub-national fertility trends in Austria, Germany and Switzerland. Comparative Population Studies, 36(2-3), 615-660.

Beaujouan, E., Brzozowska, Z., \& Zeman, K. (2016). The limited effect of increasing educational attainment on childlessness trends in twentieth-century Europe, women born 1916-65. Population Studies, 70(3), 275-291.

Berrington, A., Stone, J., \& Beaujouan, E. (2015). Educational differences in timing and quantum of childbearing in Britain: A study of cohorts born 1940- 1969. Demographic Research, 33(26), 733764.

Berry, C. R., \& Glaeser, E. L. (2005). The divergence of human capital levels across cities. Papers in regional science, $84(3), 407-444$.

Billingsley, S. (2010). The post-communist fertility puzzle. Population Research and Policy Review, 29(2), 193-231.

Bryant, J. (2007). Theories of fertility decline and the evidence from development indicators. Population and Development Review, 33(1), 101-127.

Bujard, M., \& Scheller, M. (2017). Impact of Regional Factors on Cohort Fertility: New Estimations at the District Level in Germany. Comparative Population Studies, 42(2017), 55-88.

Cambridge Econometrics. (2018). European Regional Database. Cambridge: Cambridge Econometrics.

Dawkins, C. J. (2006). Are social networks the ties that bind families to neighborhoods? Housing Studies, 21(6), 867-881.

de Beer, J., \& Deerenberg, I. (2007). An explanatory model for projecting regional fertility differences in the Netherlands. Population Research and Policy Review, 26(5-6), 511-528.

de Meester, E., \& Van Ham, M. (2009). Symmetry and asymmetry in working and commuting arrangements between partners in the Netherlands: does the residential context matter? Environment and Planning A, 41(9), 2181-2200.

Dettling, L. J., \& Kearney, M. S. (2014). House prices and birth rates: The impact of the real estate market on the decision to have a baby. Journal of Public Economics, 110(2014), 82-100.

Dommermuth, L., \& Klüsener, S. (2019). Formation and realisation of moving intentions across the adult life course. Population, Space and Place, 25(5), e2212.

Dunford, M. (1996). Disparities in employment, productivity and output in the EU: the roles of labour market governance and welfare regimes. Regional Studies, 30(4), 339-357.

Esping-Andersen, G. (2009). Incomplete revolution: Adapting welfare states to women's new roles. Cambridge: Polity.

Eurostat. (2011). Regions in the European Union. Nomenclature of territorial units for statistics NUTS 2010/EU-27. (2011 ed.). Luxemburg: European Union.

Eurostat. (2018). Gross domestic product (GDP) at current market prices by NUTS 3 regions. Retrieved 1.5.2018, from Eurostat http://ec.europa.eu/eurostat/web/products-datasets/Lnama 10r 3gdp

Eurostat. (2019). Population aged 30-34 by educational attainment level, sex, and NUTS 2 regions (\%). Retrieved 28.6.2019, from Eurostat https://ec.europa.eu/eurostat/data/database

Federal Statistical Office and Statistical Offices of the Federal States. (2018). German Microcensus 2008, 2012, 2016, own calculations. 
Fiori, F., Graham, E., \& Feng, Z. (2014). Geographical variations in fertility and transition to second and third birth in Britain. Advances in Life Course Research, 21(2014), 149-167.

Flynn, L. (2017). Delayed and depressed: from expensive housing to smaller families. International Journal of Housing Policy, 17(3), 374-395.

Fox, J., Klüsener, S., \& Myrskylä, M. (2019). Is a Positive Relationship Between Fertility and Economic Development Emerging at the Sub-National Regional Level? Theoretical Considerations and Evidence from Europe. European Journal of Population, 35(3), 487-518.

Golden, L. (2001). Flexible work schedules: Which workers get them? American Behavioral Scientist, 44(7), 1157-1178.

Gustafsson, S., \& Kalwij, A. (2006). Education and postponement of maternity: economic analyses for industrialized countries. European Studies of Population (Vol. 15). Dordrecht: Springer.

Hank, K. (2002). Regional social contexts and individual fertility decisions: A multilevel analysis of first and second births in Western Germany. European Journal of Population, 18(3), 281-299.

Huinink, J., \& Kohli, M. (2014). A life-course approach to fertility. Demographic Research, 30(45), 12931326.

INSEE. (2013). Calcul des pondérations de l'enquête Famille et Logements, Note N 137/DG75-F170/. Retrieved 8.7.2019 https://liliefl2011.site.ined.fr/fichier/s rubrique/20511/137calcul.des.pond.rations.de.la.enqu.te.efl2011. $\underline{\text { en.pdf }}$

INSEE. (2014). Apurements et imputations dans l'Enquête famille et logements 2011, Note $\mathrm{N}^{\circ}$ 714/DG75-F170/. Retrieved 8.7.2019 https://liliefl2011.site.ined.fr/fichier/s rubrique/20511/apurements.et.imputations.dans.la.enqu.te1.en.p df

IPUMS. (2018). Minnesota Population Center. Integrated Public Use Microdata Series, International: Version 7.0 [dataset]. Retrieved 5.3.2018, from IPUMS.

Jalovaara, M., Neyer, G., Andersson, G., Dahlberg, J., Dommermuth, L., Fallesen, P., \& Lappegård, T. (2019). Education, gender, and cohort fertility in the Nordic countries. European Journal of Population, 35(3), 563-586.

Klesment, M., Puur, A., Rahnu, L., \& Sakkeus, L. (2014). Varying association between education and second births in Europe: comparative analysis based on the EU-SILC data. Demographic Research, 31(27), 813-860.

Konietzka, D., \& Kreyenfeld, M. (2010). The growing educational divide in mothers' employment: an investigation based on the German micro-censuses 1976-2004. Work, employment and society, 24(2), 260-278.

Kosfeld, R., Eckey, H.-F., \& Lauridsen, J. (2007). Disparities in prices and income across German NUTS 3 regions. Volkswirtschaftliche Diskussionsbeiträge 93. University of Kassell. Kassell.

Kravdal, $\varnothing$. (2002). The impact of individual and aggregate unemployment on fertility in Norway. Demographic Research, 6(10), 263-294.

Kravdal, $\varnothing$., \& Rindfuss, R. R. (2008). Changing relationships between education and fertility: A study of women and men born 1940 to 1964. American Sociological Review, 73(5), 854-873.

Kreyenfeld, M. (2006). Der Einfluss der ,Wende'auf bildungsspezifische Fertilitätsunterschiede in Ostdeutschland. MPIDR Working Paper WP 2006-025.

Kreyenfeld, M., \& Andersson, G. (2014). Socioeconomic differences in the unemployment and fertility nexus: Evidence from Denmark and Germany. Advances in Life Course Research, 21(2014), 5973.

Kreyenfeld, M., \& Konietzka, D. (2017). Childlessness in Europe: Contexts, Causes, and Consequences. Dordrecht, the Netherlands: Springer. 
Kulu, H. (2008). Fertility and spatial mobility in the life course: evidence from Austria. Environment and Planning A, 40(3), 632-652.

Kulu, H. (2013). Why do fertility levels vary between urban and rural areas? Regional Studies, 47(6), 895912.

Kulu, H., Vikat, A., \& Andersson, G. (2007). Settlement size and fertility in the Nordic countries. Population Studies, 61(3), 265-285.

Kulu, H., \& Washbrook, E. (2014). Residential context, migration and fertility in a modern urban society. Advances in Life Course Research, 21(2014), 168-182.

Kurre, J. A. (2003). Is the cost of living less in rural areas? International Regional Science Review, 26(1), 86-116.

Lee, R. (2003). The demographic transition: three centuries of fundamental change. Journal of Economic Perspectives, 17(4), 167-190.

Longford, N. T. (1999). Multivariate shrinkage estimation of small area means and proportions. Journal of the Royal Statistical Society: Series A (Statistics in Society), 162(2), 227-245.

Luci-Greulich, A., \& Thévenon, O. (2013). The impact of family policies on fertility trends in developed countries. European Journal of Population, 29(4), 387-416.

Matysiak, A., \& Vignoli, D. (2008). Fertility and women's employment: A meta-analysis. European Journal of Population, 24(4), 363-384.

Michielin, F. (2004). Lowest low fertility in an urban context: The role of migration in Turin, Italy. Population, Space and Place, 10(4), 331-347.

Mulder, C. H. (2013). Family dynamics and housing: Conceptual issues and empirical findings. Demographic Research, 29(14), 355-378.

Myrskylä, M., Kohler, H.-P., \& Billari, F. C. (2009). Advances in development reverse fertility declines. Nature, 460(7256), 741-743.

Neels, K., \& De Wachter, D. (2010). Postponement and recuperation of Belgian fertility: how are they related to rising female educational attainment? Vienna Yearbook of Population Research, 8, 77106.

Neuwirth, N. (2015). Generations and Gender Survey Austria Wave 1 \& Wave 2: Study Documentation. University of Vienna. Vienna. Retrieved from https://www.ggpi.org/sites/default/files/documents/ggs-w1 v.4.2.w2 v.1.2.aut.pdf

Neyer, G., \& Hoem, J. M. (2008). Education and Permanent Childlessness: Austria vs. Sweden. A Research Note. In J. Surkyn \& P. V. B. J. Deboosere (Eds.), Demographic Challenges for the 21st Century: A State of the Art in Demography. A State of the Art in Demography: Conference Organized as a Tribute to the Continuing Endeavours of Prof. Dr. Em. Ron Lesthaeghe in the Field of Demography. (pp. 91-112). Brussels: VUBPRESS Brussels University Press.

Openshaw, S. (1984) The modifiable areal unit problem. Concepts and Techniques in Modern Geography 38. Norwich: Geo Books.

Petrakos, G. (2001). Patterns of regional inequality in transition economies. European Planning Studies, 9(3), 359-383.

Rao, J. N. (2014). Small-Area Estimation. Wiley StatsRef: Statistics Reference Online, 1-8.

Rindfuss, R. R., Guilkey, D. K., Morgan, S. P., \& Kravdal, Ø. (2010). Child-care availability and fertility in Norway. Population and Development Review, 36(4), 725-748.

Skirbekk, V. (2008). Fertility trends by social status. Demographic Research, 18(5), 145-180.

Snyder, R. (2001). Scaling down: The subnational comparative method. Studies in comparative international development, 36(1), 93-110.

Sobotka, T. (2011). Fertility in Central and Eastern Europe after 1989: Collapse and gradual recovery. Historical Social Research, 36(2), 246-296. 
Sobotka, T. (2017). Childlessness in Europe: Reconstructing long-term trends among women born in 1900-1972. In M. Kreyenfeld \& D. Konietzka (Eds.), Childlessness in Europe: Contexts, Causes, and Consequences (pp. 17-53). Dordrecht, the Netherlands: Springer.

Sobotka, T., Beaujouan, É., \& Brzozowska, Z. (2018). Reversals, diminishing differentials or stable patterns? Long-term trends in educational gradients in fertility across the developed countries. Paper presented at the European Population Conference, Brussels.

Sobotka, T., Beaujouan, E., \& Van Bavel, J. (2017). Introduction: education and fertility in low-fertility settings. Vienna Yearbook of Population Research, 15(2017), 1-16.

Statistics Austria. (2018). Standard-documentation Meta information (Definitions, comments, methods, quality) on Microcensus since 2004 - Labour Force and Housing Survey. Retrieved 10.7.2019 https://www.statistik.at/wcm/idc/idcplg?ldcService=GET PDF FILE\&RevisionSelectionMethod= LatestReleased\&dDocName $=117000$

Thomas, M. J. (2019). Employment, education, and family: Revealing the motives behind internal migration in Great Britain. Population, Space and Place, 25(4), e2233.

Thomson, E., Winkler-Dworak, M., \& Kennedy, S. (2013). The standard family life course: An assessment of variability in life course pathways. In A. Evans \& J. Baxter (Eds.), Negotiating the Life Course: Stability and Change in Life Pathways, Life Course Research and Policies 1 (pp. 35-52). Dordrecht: Springer.

Van Bavel, J., Klesment, M., Beaujouan, E., Brzozowska, Z., Puur, A., Reher, D., . . Sobotka, T. (2018). Seeding the gender revolution: Women's education and cohort fertility among the baby boom generations. Population Studies, 72(3), 283-304.

Veltz, P. (2014). Mondialisation, villes et territoires: L'économie d'archipel. Paris cedex 14, France: Presses Universitaires de France.

Verwiebe, R., Troger, T., \& Riederer, B. (2014) Lebensqualität in Wien 1995-2013. Sozialwissenschaftliche Grundlagenforschung II [Quality of Life in Vienna 1995-2013. Basic Social Research II] Werkstattbericht 147. Vienna: City of Vienna.

Wood, J., Klüsener, S., Neels, K., \& Myrskylä, M. (2017). Is a positive link between human development and fertility attainable? Insights from the Belgian vanguard case. MPIDR Working Paper WP 2017-014. MPIDR. Rostock.

Wood, J., \& Neels, K. (2017). First a job, then a child? Subgroup variation in women's employmentfertility link. Advances in Life Course Research, 33, 38-52.

Wood, J., Neels, K., \& Kil, T. (2014). The educational gradient of childlessness and cohort parity progression in 14 low fertility countries. Demographic Research, 31(46), 1365-1416.

Zeman, K., Beaujouan, É., Brzozowska, Z., \& Sobotka, T. (2018). Cohort fertility decline in low fertility countries: Decomposition using parity progression ratios. Demographic Research, 38(25), 651690. 
Table 1 Data sources of the study in 15 European countries

\begin{tabular}{llllll} 
Country & Cohorts & \multicolumn{2}{l}{ Sample (\%) Data type } & Measurement date & Age at measurement \\
\hline Austria & $1965-1970$ & $>1$ & Microcensus+survey & $2012-2013 / 2016^{1}$ & $42-46$ \\
Belarus & $1965-1968$ & 10 & Census & $14 .-24.10 .2009$ & $41-45$ \\
Belgium & $1964-1966$ & 100 & Register & $31.12 .2006^{2}$ & $40-42$ \\
Finland & $1966-1970$ & 10 & Register & $31.12 .2012^{3}$ & $42-46$ \\
France & $1965-1970$ & 1 & Survey & 26.2 .2011 & $40-45$ \\
Germany & $1964-1970$ & 1 & Microcensus & $2008 / 2012 / 2016^{4}$ & $41-48$ \\
Greece & $1965-1970$ & 10 & Census & $10 .-20.5 .2011$ & $40-46$ \\
Hungary & $1966-1970$ & 100 & Census & 1.10 .2011 & $41-45$ \\
Ireland & $1965-1970$ & 10 & Census & 10.4 .2011 & $41-45$ \\
Lithuania & $1966-1970$ & 100 & Census & 1.3 .2011 & $41-45$ \\
Netherlands & $1966-1970$ & 100 & Register & 31.12 .2011 & $41-43$ \\
Norway & $1966-1970$ & 100 & Register & 31.12 .2011 & $41-45$ \\
Romania & $1965-1970$ & 10 & Census & $20 .-31.10 .2011$ & $40-45$ \\
Spain & $1966-1970$ & 9 & Census & 11.1 .2011 & $41-45$ \\
Sweden & $1966-1970$ & 100 & Register & 31.12 .2012 & $40-44$ \\
\hline
\end{tabular}

${ }^{1}$ Data sources in Austria are microcensuses in 2012 ( $4^{\text {th }}$ quarter) and 2016 ( $4^{\text {th }}$ quarter), Austrian Gender and Generations Survey gathered from September 2012 to March 2013, and Basic Social Science Research for Vienna Survey gathered from October 2012 to July 2013. ${ }^{2}$ In Belgium, education is measured in the census conducted on 1 October 2001 when women were aged 34 to $37 .{ }^{3}$ In Finland, education and region were measured on 31 December 2007 when women were aged 37 to $41 .{ }^{4}$ Data sources for Germany are microcensuses in 2008, 2012, and 2016 gathered throughout the year. 
Table 2 Cohort fertility rate of women by educational attainment in 15 European countries.

\begin{tabular}{lccccccc} 
COUNTRY & High & Medium & Low & Total & $\Delta$ High-Medium $\Delta$ Medium-Low & $\Delta$ High-Low \\
\hline Austria & 1.38 & 1.62 & 1.98 & 1.61 & -0.19 & -0.33 & -0.52 \\
Belarus & 1.43 & 1.76 & 1.96 & 1.68 & -0.29 & -0.14 & -0.44 \\
Belgium & 1.74 & 1.65 & 1.78 & 1.72 & 0.10 & -0.11 & -0.01 \\
Finland & 1.81 & 1.99 & 1.97 & 1.90 & -0.15 & -0.01 & -0.16 \\
France & 1.76 & 1.87 & 2.10 & 1.87 & -0.09 & -0.22 & -0.31 \\
Germany & 1.40 & 1.51 & 1.67 & 1.50 & -0.11 & -0.16 & -0.27 \\
Greece & 1.54 & 1.69 & 2.09 & 1.76 & -0.14 & -0.33 & -0.48 \\
Hungary & 1.66 & 1.77 & 2.42 & 1.86 & -0.10 & -0.59 & -0.69 \\
Ireland & 1.88 & 2.10 & 2.38 & 2.09 & -0.22 & -0.28 & -0.50 \\
Lithuania & 1.56 & 1.90 & 2.06 & 1.80 & -0.29 & -0.14 & -0.43 \\
Netherlands & 1.71 & 1.82 & 1.89 & 1.81 & -0.10 & -0.03 & -0.12 \\
Norway & 1.99 & 2.04 & 2.05 & 2.02 & -0.01 & -0.02 & -0.03 \\
Romania & 1.12 & 1.57 & 2.28 & 1.65 & -0.42 & -0.68 & -1.10 \\
Spain & 1.34 & 1.48 & 1.71 & 1.46 & -0.14 & -0.14 & -0.28 \\
Sweden & 1.93 & 1.94 & 2.04 & 1.94 & 0.00 & -0.10 & -0.10 \\
\hline & 1.62 & 1.78 & 2.03 & 1.78 & -0.14 & -0.22 & -0.36
\end{tabular}




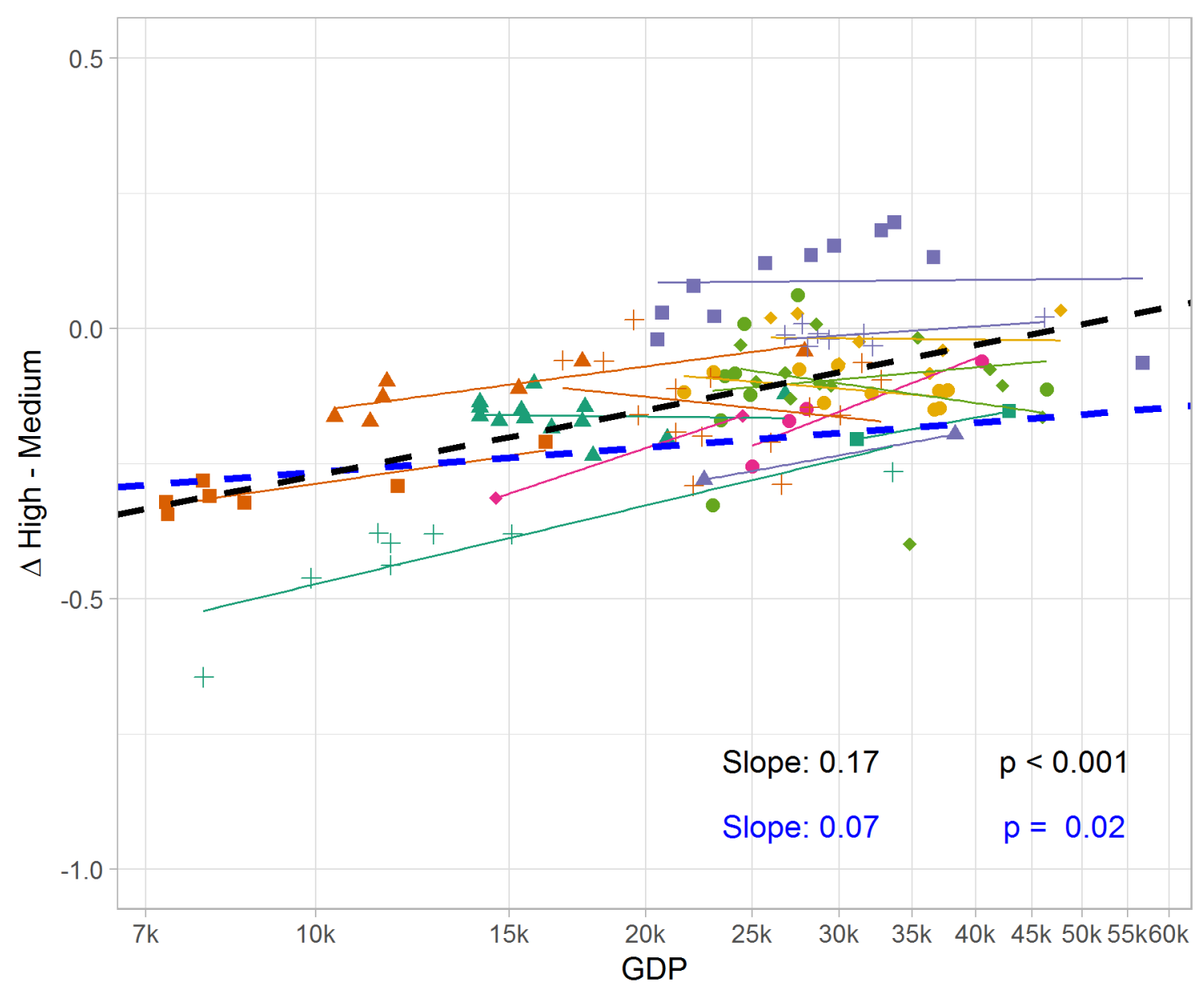

$\rightarrow$ Austria $\rightarrow$ Finland - Greece $\rightarrow$ Lithuania $\rightarrow$ Romania
- Belarus $\rightarrow$ France - Hungary $\rightarrow$ Netherlands $\rightarrow$ Spain
$\rightarrow-$ Belgium $\rightarrow$ Germany - Ireland $\rightarrow$ Norway $\rightarrow$ Sweden

Figure 1A The difference in cohort fertility rate between high- and medium-educated women according to the GDP per capita level of the region in 15 European countries. Regression lines are fitted for the global trend without (black dashed line) and with (blue dashed line) country fixed effects, and for the within-country trends for each country separately (solid lines). 


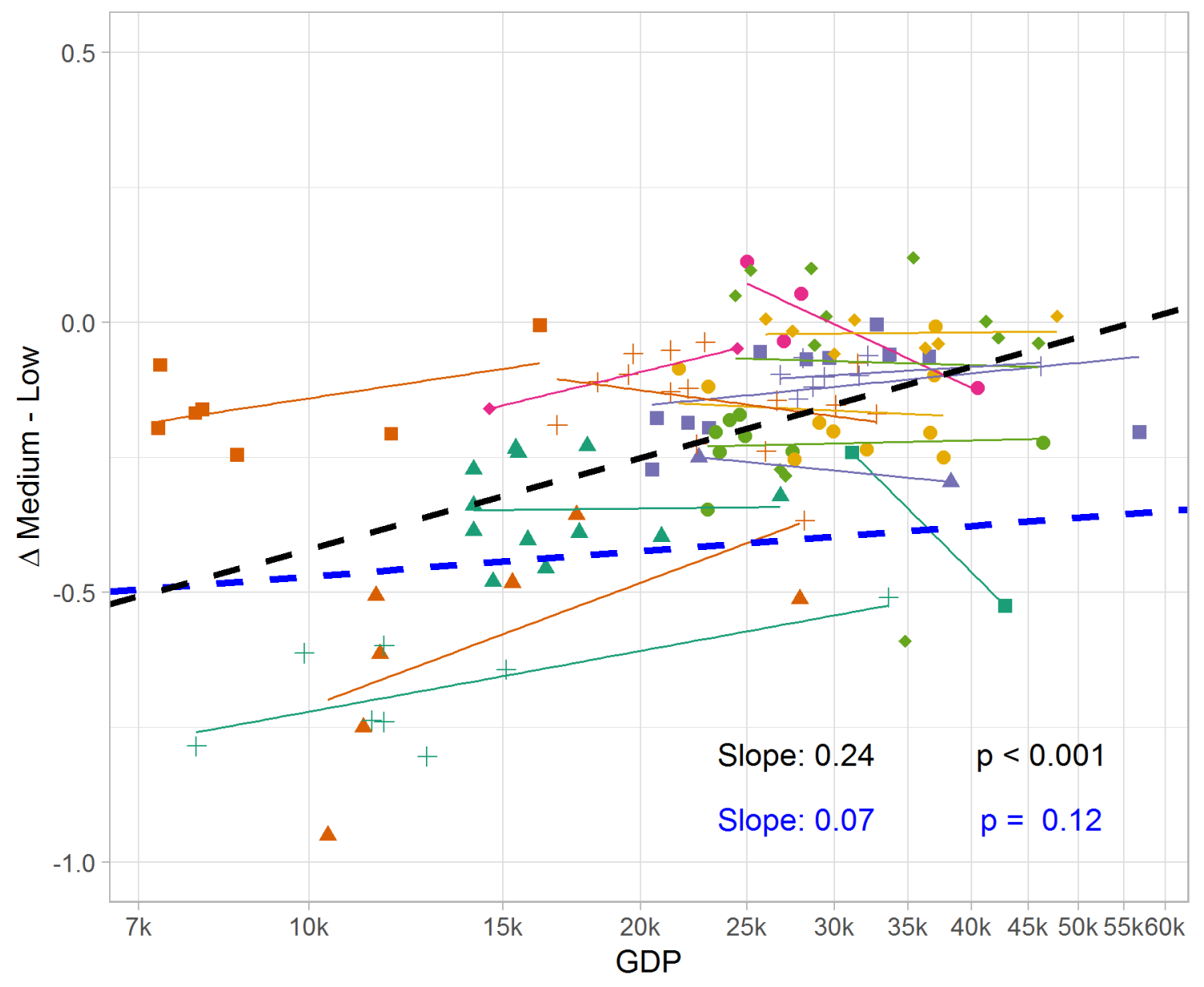

- Austria $\rightarrow$ Finland $\leftarrow$ Greece $\rightarrow$ Lithuania $\rightarrow$ Romania
- Belarus $\rightarrow$ France $\leftarrow$ Hungary $\rightarrow$ Netherlands + Spain
- Belgium $\rightarrow-$ Germany - Ireland $\rightarrow$ Norway $\rightarrow$ Sweden

Figure 1B The difference in cohort fertility rate between medium- and low-educated women according to the GDP per capita level of the region in 15 European countries. Regression lines are fitted for the global trend without (black dashed line) and with (blue dashed line) country fixed effects, and for the within-country trends for each country separately (solid lines). 


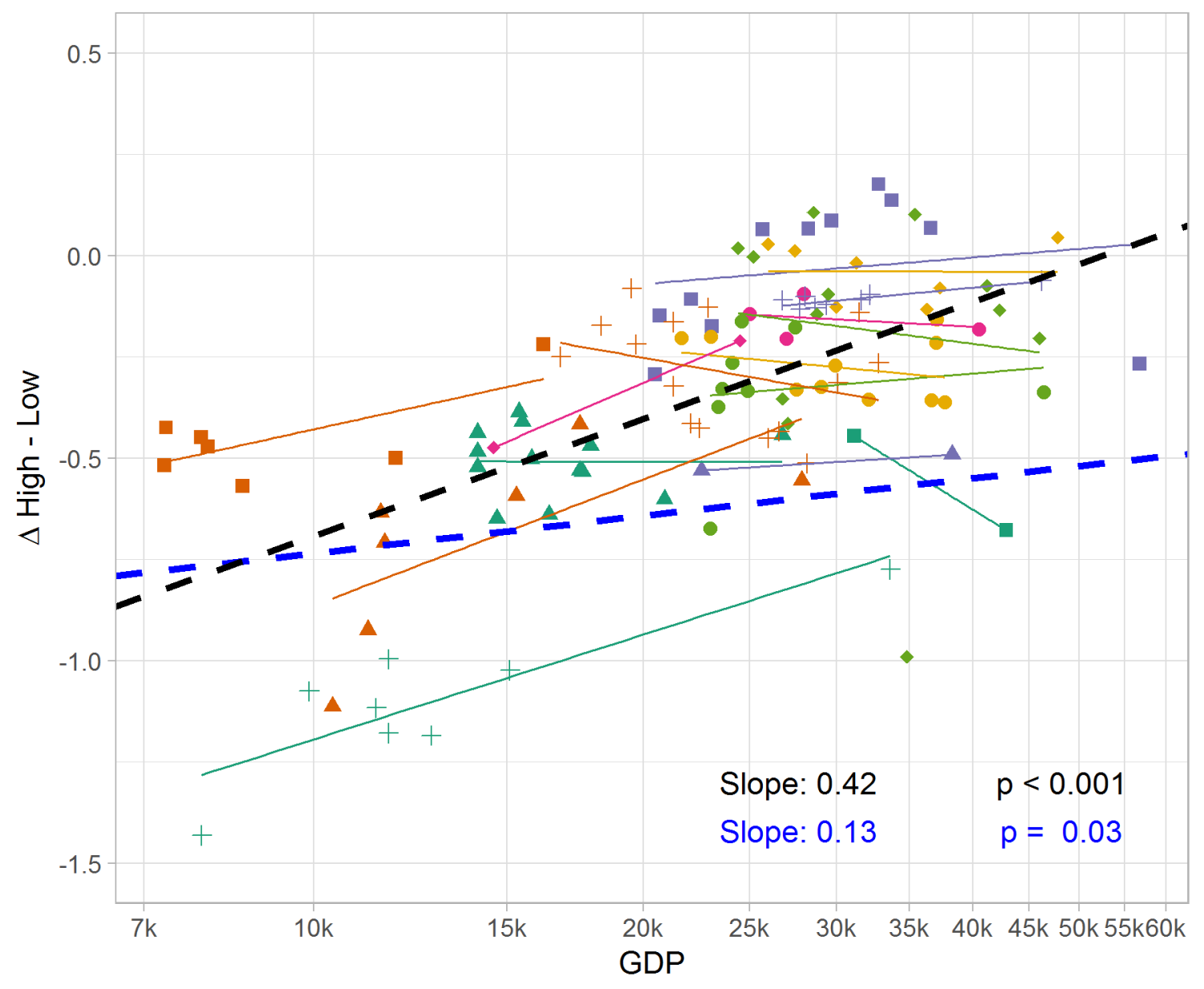

$\rightarrow$ Austria $\rightarrow$ Finland $\leftarrow$ Greece $\rightarrow$ Lithuania $\rightarrow$ Romania
- Belarus $\rightarrow$ France - Hungary $\rightarrow$ Netherlands $\rightarrow$ Spain
$\rightarrow-$ Belgium $\rightarrow$ Germany - Ireland $\rightarrow$ Norway $\rightarrow$ Sweden

Figure 1C The difference in cohort fertility rate between high- and low-educated women according to the GDP per capita level of the region of the 15 European countries. Regression lines are fitted for the global trend without (black dashed line) and with (blue dashed line) country fixed effects, and for the within-country trends for each country separately (solid lines). 


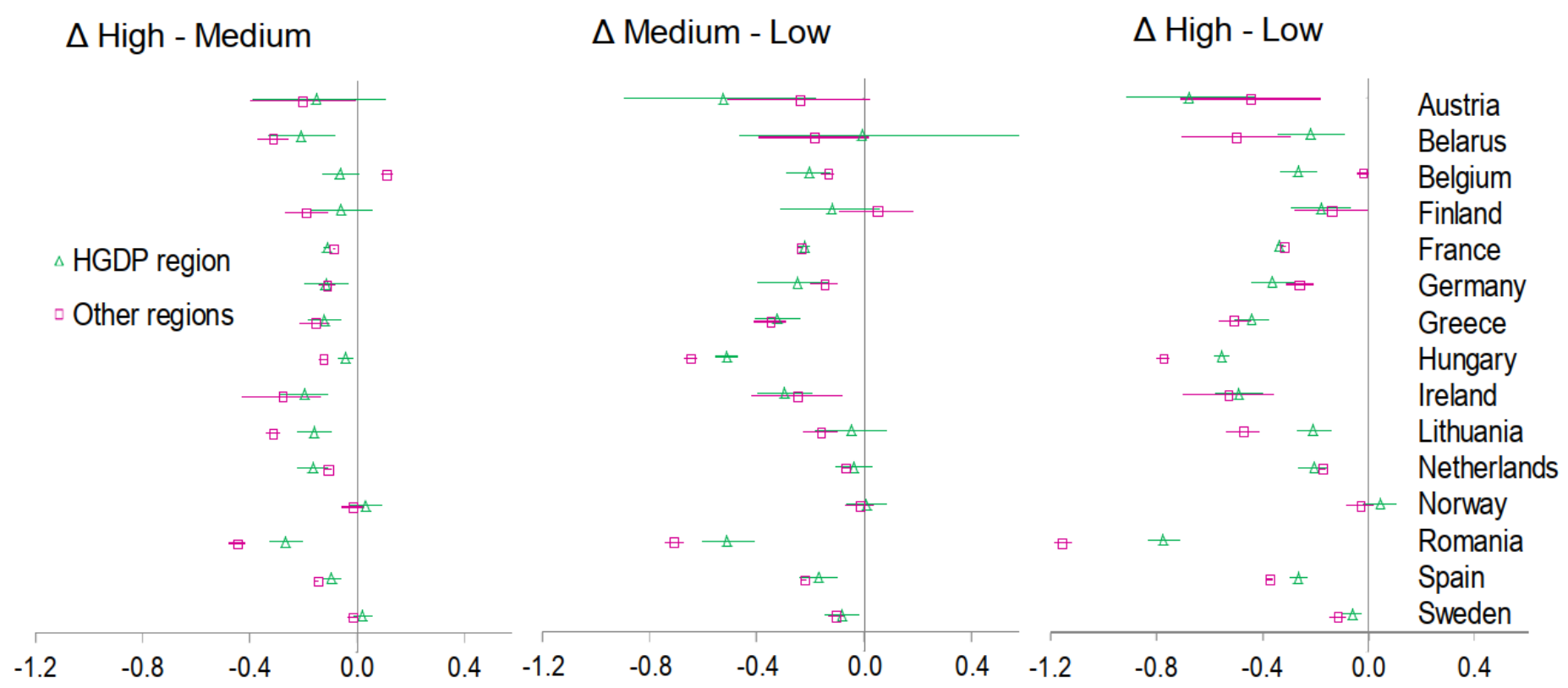

Figure 2 The difference in cohort fertility rate between two educational groups of women by country: the region with the highest GDP per capita value (HGDP region) and other regions of a country in 15 European countries. Figures also display $95 \%$ credible intervals of the point estimates with horizontal lines. 
Appendix 1 Description of the sub-national regional categorisation in 15 European countries

The NUTS categorisation is strongly linked to existing administrative divisions in a country, and also considers the general character and population size of the region. This categorisation has three levels, and we generally aimed to use the NUTS 2 level, which covers regions with between 800,000 and three million inhabitants. At the NUTS 1 level, on the other hand, many smaller countries would consist of one region only. NUTS 2-level data were analysed for Belarus, Belgium, Finland, Greece, Hungary, Ireland, the Netherlands, Norway, Romania, Spain, and Sweden. These regions generally have populations between 800,000 and three million inhabitants. In Austria, France, and Germany, limited sample sizes forced us to conduct the analysis at a higher level of geographic detail. In Austria, the capital city of Vienna (NUTS 2) was compared with the rest of the country. For France, we excluded overseas territories, and used the NUTS 1 level. For Germany, a modified version of the NUTS 1 level was used to compensate for the small numbers in some regions due to the sample used. For Finland, we excluded the Åland islands; and for Spain, we excluded the Canary Islands and the Balearic Islands, Ceuta and Melilia, due to their small population sizes and distinct cultures. For Lithuania, which back in 2011 consisted of just one NUTS 2 region, we separated out the capital city of Vilnius (a LAU1 level unit in the classification of Eurostat) from the rest of Lithuania. Belarus is not an EU country, but a corresponding classification has been developed for it; please see http://riate.cnrs.fr/wpcontent/uploads/2015/03/M4D_20121220_TR_russia.pdf. 
Appendix 2 Descriptive characteristics of the study population by sub-national region in 15 European countries

\begin{tabular}{|c|c|c|c|c|c|c|}
\hline Country & Region & High, \% & Medium, \% & Low, \% & $\mathrm{N}$ & GDP per capita \\
\hline \multirow[t]{3}{*}{ Austria } & Vienna & 32 & 62 & 7 & 813 & 42,900 \\
\hline & Rest of Austria & 19 & 65 & 16 & 1,893 & 31,147 \\
\hline & Total & 23 & 64 & 13 & 2,706 & 37,023 \\
\hline \multirow[t]{8}{*}{ Belarus } & Minsk city & 40 & 60 & 0 & 3,922 & 16,209 \\
\hline & Minsk & 20 & 78 & 3 & 3,533 & 11,879 \\
\hline & Gomel & 21 & 76 & 3 & 3,474 & 8,604 \\
\hline & Brest & 23 & 76 & 2 & 3,411 & 7,329 \\
\hline & Vitebsk & 24 & 75 & 2 & 2,996 & 7,886 \\
\hline & Grodno & 24 & 75 & 1 & 2,904 & 8,003 \\
\hline & Mogilev & 21 & 77 & 2 & 2,664 & 7,300 \\
\hline & Total & 25 & 73 & 2 & 22,904 & 9,601 \\
\hline \multirow[t]{12}{*}{ Belgium } & Brussels & 49 & 25 & 26 & 9,753 & 56,800 \\
\hline & Antwerp & 36 & 41 & 23 & 33,484 & 36,600 \\
\hline & Brabant Walonne & 50 & 28 & 22 & 6,910 & 33,700 \\
\hline & Vlaams Brabant & 46 & 36 & 18 & 22,053 & 32,800 \\
\hline & West Flanders & 32 & 39 & 29 & 24,065 & 29,700 \\
\hline & East Flanders & 36 & 38 & 27 & 29,704 & 28,300 \\
\hline & Limburg & 33 & 40 & 27 & 16,818 & 25,700 \\
\hline & Liège & 33 & 34 & 34 & 18,787 & 23,100 \\
\hline & Namur & 35 & 35 & 31 & 8,980 & 22,100 \\
\hline & Luxembourg & 35 & 35 & 30 & 4,884 & 20,700 \\
\hline & Hainaut & 29 & 34 & 37 & 23,647 & 20,500 \\
\hline & Total & 36 & 36 & 27 & 199,085 & 30,000 \\
\hline \multirow[t]{5}{*}{ Finland } & Helsinki-Uusimaa & 58 & 32 & 10 & 5,118 & 40,500 \\
\hline & West Finland & 50 & 42 & 9 & 3,848 & 28,000 \\
\hline & South Finland & 48 & 42 & 10 & 3,317 & 27,000 \\
\hline & North and East Finland & 50 & 42 & 8 & 3,419 & 25,000 \\
\hline & Total & 52 & 39 & 9 & 15,702 & 30,125 \\
\hline \multirow[t]{9}{*}{ France } & Parisian region & 49 & 36 & 15 & 352,428 & 46,400 \\
\hline & Central East France & 35 & 49 & 16 & 270,447 & 27,500 \\
\hline & Mediterranean France & 35 & 48 & 18 & 291,688 & 24,900 \\
\hline & South West France & 37 & 48 & 15 & 246,325 & 24,600 \\
\hline & West France & 34 & 50 & 16 & 321,986 & 24,100 \\
\hline & Paris Basin & 28 & 50 & 22 & 400,242 & 23,600 \\
\hline & East France & 30 & 51 & 19 & 194,127 & 23,400 \\
\hline & North France & 31 & 45 & 24 & 148,062 & 23,000 \\
\hline & Total & 35 & 47 & 18 & $2,225,305$ & 27,188 \\
\hline \multirow[t]{11}{*}{ Germany } & Hesse & 26 & 65 & 9 & 4,565 & 37,672 \\
\hline & Bavaria & 23 & 68 & 9 & 10,408 & 37,050 \\
\hline & Baden-Wuerttemberg & 25 & 66 & 9 & 7,844 & 36,987 \\
\hline & Schleswig-Holstein and Hamburg & 25 & 65 & 9 & 3,844 & 36,640 \\
\hline & North Rhine-Westphalia & 22 & 67 & 12 & 13,423 & 32,095 \\
\hline & Lower Saxony and Bremen & 19 & 69 & 12 & 6,972 & 29,919 \\
\hline & Rhineland Palatinate and Saarland & 20 & 68 & 12 & 3,928 & 29,070 \\
\hline & Berlin and Brandenburg & 37 & 58 & 5 & 4,752 & 27,583 \\
\hline & Saxony and Thuringia & 33 & 65 & 2 & 5,208 & 23,044 \\
\hline & Mecklenburg-Western Pomerania & 28 & 67 & 5 & 3,351 & 21,676 \\
\hline & Total & 25 & 66 & 9 & 64,295 & 31,174 \\
\hline
\end{tabular}


Appendix 2 continues

\begin{tabular}{|c|c|c|c|c|c|c|}
\hline Country & Region & High, \% & Medium, \% & Low, \% & $\mathrm{N}$ & GDP per capita \\
\hline \multirow[t]{14}{*}{ Greece } & Attiki & 34 & 49 & 18 & 14726 & 26,800 \\
\hline & Notio Aigaio & 17 & 40 & 43 & 1075 & 20,900 \\
\hline & Dytiki Makedonia & 25 & 37 & 39 & 1111 & 17,900 \\
\hline & Ionia Nisia & 22 & 42 & 36 & 766 & 17,600 \\
\hline & Sterea Ellada & 22 & 42 & 37 & 2048 & 17,500 \\
\hline & Kriti & 25 & 41 & 33 & 2248 & 16,400 \\
\hline & Peloponnisos & 22 & 42 & 36 & 1964 & 15,800 \\
\hline & Voreio Aigaio & 26 & 38 & 36 & 673 & 15,500 \\
\hline & Kentriki Makedonia & 30 & 41 & 29 & 6990 & 15,400 \\
\hline & Dytiki Ellada & 22 & 39 & 39 & 2600 & 14,700 \\
\hline & Anatoliki Makedonia, Thraki & 22 & 34 & 44 & 2112 & 14,100 \\
\hline & Ipeiros & 31 & 34 & 35 & 1140 & 14,100 \\
\hline & Thessalia & 28 & 36 & 36 & 2731 & 14,100 \\
\hline & Total & 29 & 43 & 29 & 40184 & 16,985 \\
\hline \multirow[t]{8}{*}{ Hungary } & Central Hungary & 31 & 58 & 11 & 97,031 & 27,900 \\
\hline & Western Transdanubia & 20 & 64 & 17 & 33,439 & 17,500 \\
\hline & Central Transdanubia & 19 & 62 & 20 & 36,369 & 15,300 \\
\hline & Southern Great Plain & 19 & 59 & 22 & 31,485 & 11,600 \\
\hline & Southern Transdanubia & 20 & 61 & 19 & 43,003 & 11,500 \\
\hline & Northern Great Plain & 19 & 57 & 25 & 50,040 & 11,200 \\
\hline & Northern Hungary & 19 & 59 & 22 & 40,142 & 10,400 \\
\hline & Total & 23 & 59 & 18 & 331,509 & 15,057 \\
\hline \multirow[t]{3}{*}{ Ireland } & Southern and Eastern & 35 & 41 & 24 & 10,475 & 38,300 \\
\hline & Border, Midland and Western & 33 & 42 & 25 & 3,772 & 22,600 \\
\hline & Total & 34 & 41 & 24 & 14,247 & 30,450 \\
\hline \multirow[t]{3}{*}{ Lithuania } & Vilnius & 52 & 45 & 2 & 17,445 & 24,500 \\
\hline & Rest of Lithuania & 28 & 67 & 5 & 89,592 & 14,592 \\
\hline & Total & 32 & 64 & 5 & 107,037 & 19,546 \\
\hline \multirow[t]{13}{*}{ Netherlanc } & s Groningen & 28 & 51 & 21 & 18,462 & 46,000 \\
\hline & Noord-Holland & 37 & 45 & 18 & 81,843 & 42,300 \\
\hline & Utrecht & 42 & 41 & 17 & 40,787 & 41,200 \\
\hline & Noord-Brabant & 27 & 50 & 23 & 82,607 & 35,400 \\
\hline & Zuid-Holland & 21 & 34 & 45 & 30,974 & 34,800 \\
\hline & Gelderland & 29 & 49 & 23 & 68,838 & 29,500 \\
\hline & Overijssel & 25 & 53 & 21 & 37,527 & 28,800 \\
\hline & Limburg & 24 & 51 & 25 & 36,124 & 28,600 \\
\hline & Zeeland & 20 & 56 & 24 & 12,173 & 27,100 \\
\hline & Flevoland & 26 & 50 & 24 & 12,087 & 26,800 \\
\hline & Friesland & 26 & 54 & 20 & 22,576 & 25,200 \\
\hline & Drenthe & 26 & 53 & 21 & 17,589 & 24,400 \\
\hline & Total & 29 & 48 & 23 & 461,587 & 32,508 \\
\hline \multirow[t]{8}{*}{ Norway } & Oslo and Akershus & 52 & 34 & 14 & 19,290 & 47,800 \\
\hline & Agder and Rogaland & 39 & 43 & 19 & 9,689 & 37,300 \\
\hline & Western Norway & 43 & 42 & 16 & 11,474 & 36,300 \\
\hline & Trøndelag & 44 & 41 & 15 & 6,389 & 31,300 \\
\hline & Northern Norway & 45 & 39 & 16 & 7,024 & 30,000 \\
\hline & South Eastern Norway & 36 & 43 & 20 & 15,211 & 27,500 \\
\hline & Hedmark and Oppland & 34 & 45 & 21 & 6,107 & 26,000 \\
\hline & Total & 43 & 40 & 17 & 75,184 & 33,743 \\
\hline
\end{tabular}


Appendix 2 continues

\begin{tabular}{|c|c|c|c|c|c|c|}
\hline Country & Region & High, \% & Medium, \% & Low, \% & $\mathrm{N}$ & GDP per capita \\
\hline \multirow[t]{9}{*}{ Romania } & Bucharest - Ilfov & 37 & 50 & 13 & 11,206 & 33,600 \\
\hline & West & 20 & 55 & 25 & 8,658 & 15,100 \\
\hline & Center & 19 & 60 & 22 & 10,154 & 12,800 \\
\hline & Northwest & 19 & 56 & 26 & 11,214 & 11,700 \\
\hline & South - Muntenia & 16 & 58 & 27 & 14,805 & 11,700 \\
\hline & South East & 19 & 55 & 26 & 11,485 & 11,400 \\
\hline & South-West Oltenia & 16 & 62 & 22 & 9,657 & 9,900 \\
\hline & Northeast & 16 & 56 & 28 & 13,626 & 7,900 \\
\hline & Total & 20 & 56 & 24 & 90,805 & 14,263 \\
\hline \multirow[t]{16}{*}{ Spain } & Madrid & 29 & 66 & 6 & 2,744 & 32,800 \\
\hline & Basque Community & 29 & 65 & 6 & 21,332 & 31,500 \\
\hline & Navarre & 23 & 67 & 10 & 13,219 & 30,100 \\
\hline & Catalonia & 25 & 66 & 8 & 1,345 & 28,200 \\
\hline & Aragon & 22 & 64 & 14 & 3,749 & 26,600 \\
\hline & La Rioja & 20 & 62 & 18 & 24,744 & 26,000 \\
\hline & Castile-Leon & 24 & 70 & 7 & 2,027 & 22,900 \\
\hline & Cantabria & 17 & 67 & 16 & 5,326 & 22,500 \\
\hline & Principality of Asturias & 17 & 68 & 16 & 8,905 & 22,100 \\
\hline & Galicia & 25 & 65 & 9 & 7,613 & 21,300 \\
\hline & Valencian Community & 27 & 67 & 6 & 5,595 & 21,300 \\
\hline & Murcia & 25 & 67 & 9 & 13,179 & 19,700 \\
\hline & Castille-La Mancha & 35 & 60 & 5 & 7,460 & 19,500 \\
\hline & Andalucia & 40 & 55 & 5 & 17,579 & 18,300 \\
\hline & Extremadura & 31 & 64 & 6 & 3,013 & 16,800 \\
\hline & Total & 28 & 62 & 10 & 137,830 & 23,973 \\
\hline \multirow[t]{9}{*}{ Sweden } & Stockholm & 43 & 49 & 8 & 54,235 & 46,200 \\
\hline & Upper Norrland & 41 & 51 & 9 & 14,216 & 32,200 \\
\hline & West Sweden & 37 & 53 & 9 & 52,153 & 31,600 \\
\hline & Middle Norrland & 35 & 55 & 10 & 10,780 & 29,400 \\
\hline & East Middle Sweden & 36 & 54 & 10 & 42,457 & 28,700 \\
\hline & Småland and the islands & 34 & 57 & 9 & 22,080 & 28,100 \\
\hline & South Sweden & 39 & 52 & 9 & 36,575 & 27,800 \\
\hline & North Sweden & 33 & 56 & 11 & 23,241 & 26,800 \\
\hline & Total & 38 & 53 & 9 & 255,737 & 31,350 \\
\hline
\end{tabular}

Note: Results for Austria, France, and Spain are shown as weighted. Sub-national regions within a country are ranked by the GDP per capita of the region, from highest to lowest. Population-weighted average GDP per capita was used for regions containing more than one NUTS region. In Lithuania, the GDP per capita value was not available for the chosen regional classification, and the value for Vilnius county, a larger area that also covers the surrounding areas of Vilnius city (NUTS 3 level region), had to be used as a proximate estimate. The total rows show for the GDP per capita the nonweighted country averages of the regional values. 
We use a vector-based empirical Bayesian approach to estimate region- and education-specific cohort fertility rates and their credible intervals (Assunção et al., 2005; Longford, 1999). The vector-based approach borrows strength not only from other regions in the same country based on the sample sizes of these regions and their similarity to the GDP of the region in question, but from other educational groups in the same region and from regularities in educational fertility schedules across regions. The estimation method can be described as follows. Suppose the total number of women from selected cohorts observed from country $c(c=1, \ldots, C)$, region $r\left(r=1, \ldots, R_{c}\right)$ with education level $e(e=1,2,3)$ is denoted as $\mathrm{NWomen}_{c, r, e}$ and the number of children is denoted by Child $_{c, r, e}$. The crude cohort fertility rate is denoted by $\hat{\lambda}_{c, r, e}=$ NChild $_{c, r, e} /$ NWomen $_{c, r, e}$ and $\hat{\lambda}_{c, r}=$ NChild $_{c, r} /$ NWomen $_{c, r}$, where

NWomen $_{c, r}=\left(\right.$ NWomen $_{c, r, 1}$, NWomen $_{c, r, 2}$, NWomen $\left._{c, r, 3}\right)$, and

NChild $_{c, r}=\left(\right.$ NChild $_{c, r, 1}$, NChild $_{c, r, 2}$, NChild $\left._{c, r, 3}\right)$.

Suppose the real cohort fertility rate $\lambda_{c, r, e}$ follows:

$$
\operatorname{NChild}_{c, r, e} \mid \lambda_{c, r, e} \sim \operatorname{Poisson}\left(\text { NWomen }_{c, r, e} \times \lambda_{c, r, e}\right)
$$

The distance in GDP between region $r_{1}$ of country $c_{1}$ and region $r_{2}$ of country $c_{2}$ is defined as $d_{c_{1}, c_{2} ; r_{1}, r_{2}}=\left\{\begin{array}{lr}\left|G D P_{c_{1}, r_{1}}-G D P_{c_{2}, r_{2}}\right| / \text { range }_{1 \leq c \leq C, 1 \leq r \leq R_{c}}\left(G D P_{c, r}\right) & \text { if } c_{1}=c_{2} \\ 1 & \text { if } c_{1} \neq c_{2}\end{array}\right.$

The vectorial regional shrinkage estimator for the cohort fertility rate is denoted as:

$\lambda_{c, r}^{*}=\hat{\lambda}_{c, r}+\tau_{c, r}\left(E\left(\lambda_{c, r}\right)-\hat{\lambda}_{c, r}\right)$, where $E\left(\lambda_{c, r}\right)$ is the cohort fertility rate of region $r$ and $\tau_{c, r}$ shrinking factor. $E\left(\lambda_{c, r}\right)$ is estimated as $\hat{E}\left(\lambda_{c, r}\right)=\sum_{r_{i}=1}^{R c}\left[\left(1-d_{c, c ; r, r_{i}}\right) \times \hat{\lambda}_{c, r_{2}}\right]$ by borrowing information from other regions in country $c$ according to their distances in GDP. The vectorial shrinkage estimator $\lambda_{c, r}^{*}$ shrinks a vector of regional cohort fertility rate estimates towards a more typical pattern of regional fertility estimates within a country, with more shrinkage when the distance in GDP is smaller. The shrinking factor $\tau_{c, r}$ is estimated using moments estimation, as proposed by Assunção et al., 2005, which gives larger values (i.e., more shrinkage) when the sampling noise of a regional estimate is expected to be large relative to the variability of the estimates across regions within a country. It follows that shrinkage is larger for regions with smaller sample sizes. Sensitivity analysis showed that the results were robust when different distance matrixes were defined based on the GDP. All Cls (credible intervals) were estimated based on 10,000 bootstrapping replications. The analysis was performed using $\mathrm{R}$ version 3.4.1. 
Appendix 4 Empirical Bayesian cohort fertility rate (black), 95\% credible interval (red), and observed cohort fertility rate (blue) for the high-educated by sub-national region in 15 European countries

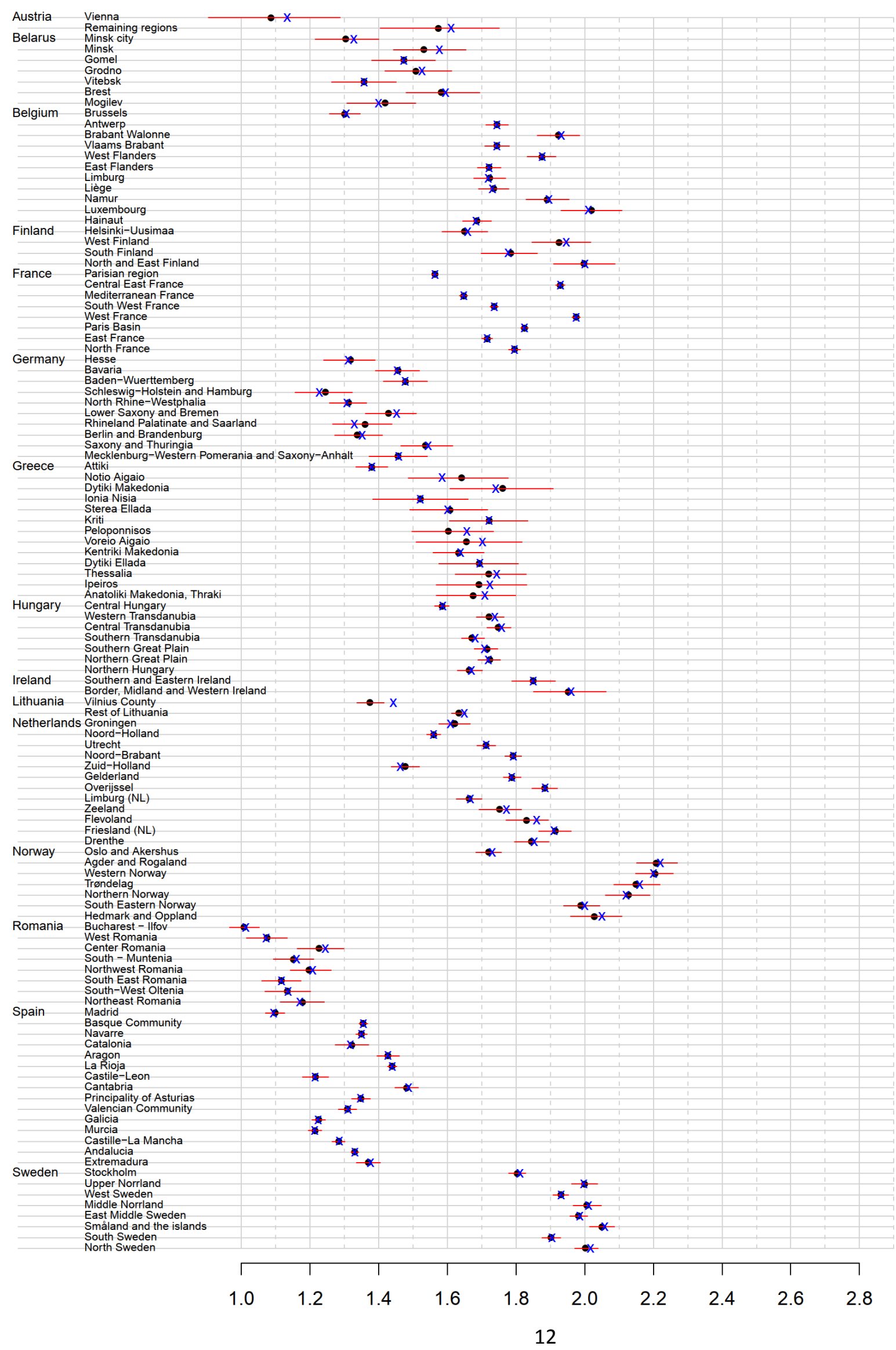


Appendix 5 Empirical Bayesian cohort fertility rate (black), 95\% credible interval (red), and observed cohort fertility rate (blue) for the medium-educated by sub-national region in 15 European countries

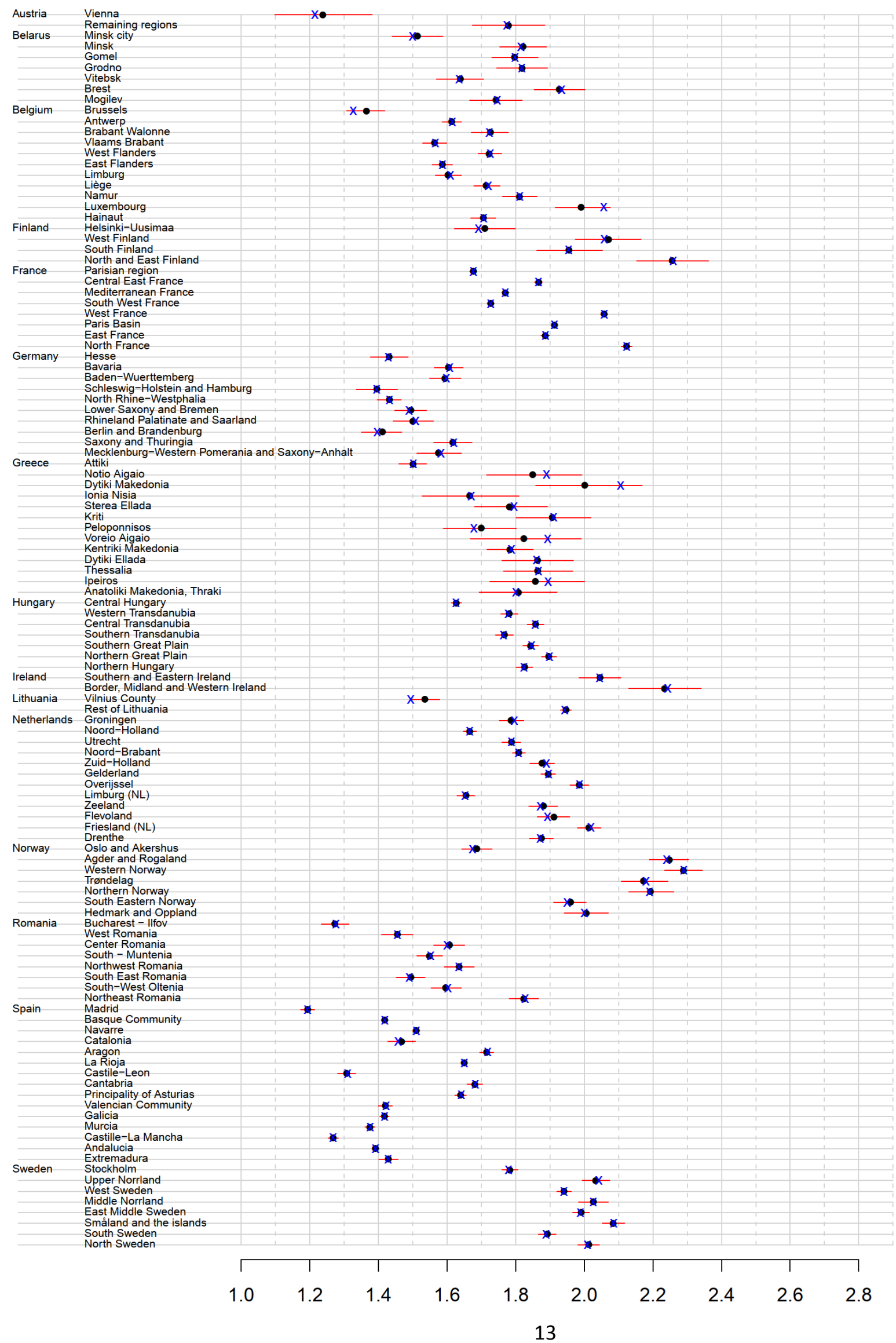


Appendix 6 Empirical Bayesian cohort fertility rate (black), 95\% credible interval (red), and observed cohort fertility rate (blue) for the low-educated by sub-national region in 15 European countries

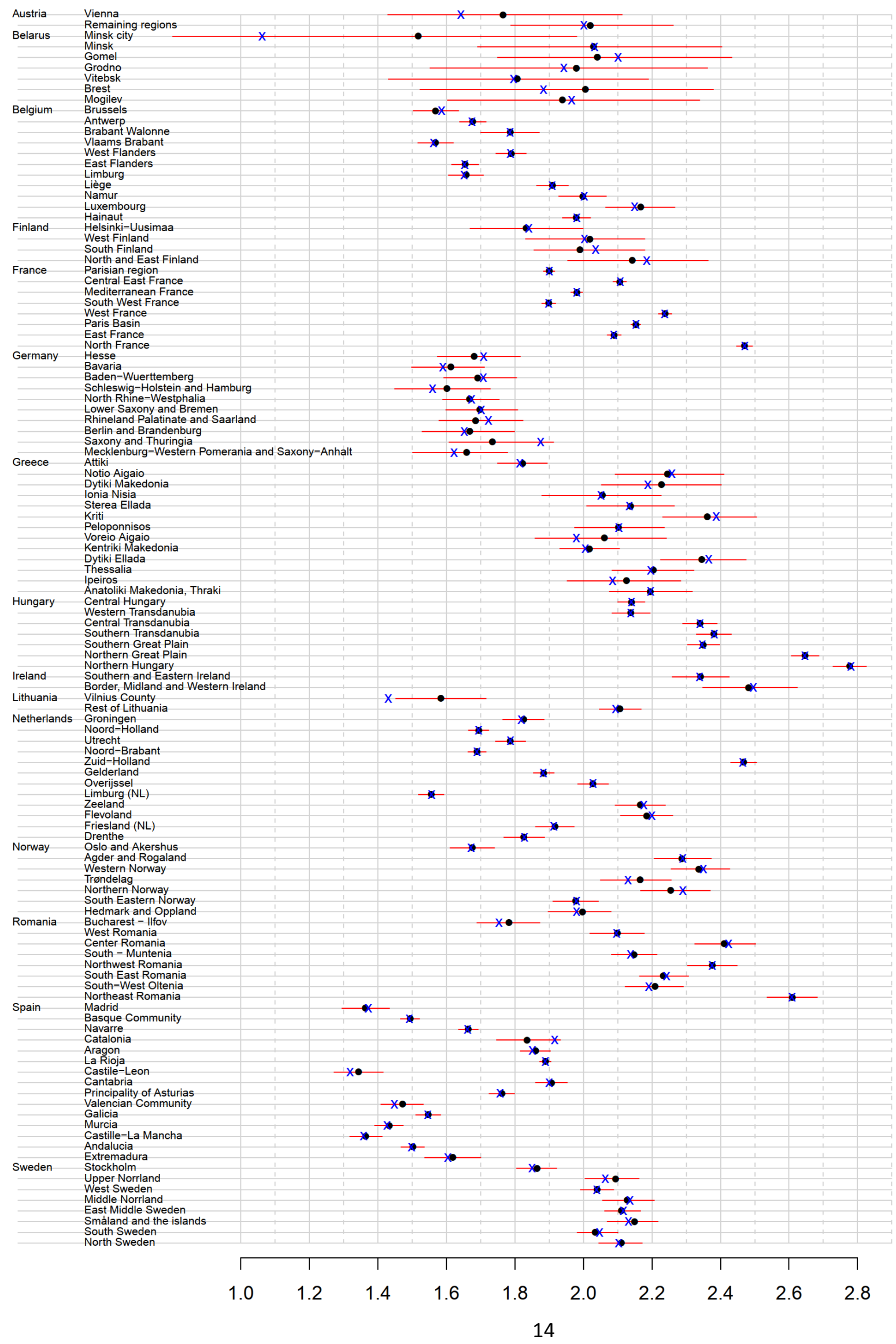


Appendix 7 Cohort fertility rate of women by educational attainment and sub-national region in 15 European countries.

Empirical Bayesian cohort fertility rates.

\begin{tabular}{|c|c|c|c|c|c|c|c|c|c|c|}
\hline \multirow{2}{*}{$\frac{\text { Country }}{\text { Austria }}$} & \multirow{2}{*}{$\begin{array}{l}\text { Region } \\
\text { Vienna }\end{array}$} & \multirow{2}{*}{$\frac{\text { High }}{1.09}$} & \multirow{2}{*}{$\frac{\text { Med }}{1.24}$} & \multirow{2}{*}{$\frac{\text { Low }}{1.77}$} & \multicolumn{2}{|c|}{$\Delta$ High - Med (95\% Cl) } & \multicolumn{2}{|c|}{$\Delta$ Med - Low $(95 \% \mathrm{Cl})$} & \multicolumn{2}{|c|}{$\Delta$ High - Low $(95 \% \mathrm{Cl}$} \\
\hline & & & & & -0.15 & $(-0.39,0.10)$ & -0.53 & $(-0.90,-0.18)$ & -0.68 & $(-1.07,-0.29)$ \\
\hline & Rest of Austria & 1.57 & 1.78 & 2.02 & -0.20 & $(-0.40,-0.01)$ & -0.24 & $(-0.51,0.02)$ & -0.45 & $(-0.74,-0.15)$ \\
\hline & Total & 1.37 & 1.62 & 1.98 & -0.19 & $(-0.35,-0.03)$ & -0.33 & $(-0.55,-0.11)$ & -0.52 & $(-0.77,-0.27)$ \\
\hline \multirow[t]{8}{*}{ Belarus } & Minsk city & 1.28 & 1.53 & 1.72 & -0.21 & $(-0.33,-0.08)$ & -0.01 & $(-0.46,0.71)$ & -0.22 & $(-0.68,0.52)$ \\
\hline & Minsk & 1.50 & 1.83 & 2.01 & -0.29 & $(-0.39,-0.15)$ & -0.21 & $(-0.59,0.13)$ & -0.50 & $(-0.87,-0.13)$ \\
\hline & Gomel & 1.48 & 1.80 & 1.98 & -0.32 & $(-0.43,-0.22)$ & -0.25 & $(-0.64,0.05)$ & -0.57 & $(-0.97,-0.27)$ \\
\hline & Brest & 1.50 & 1.82 & 2.00 & -0.31 & $(-0.41,-0.19)$ & -0.16 & $(-0.53,0.27)$ & -0.47 & $(-0.84,-0.03)$ \\
\hline & Vitebsk & 1.36 & 1.64 & 1.84 & -0.28 & $(-0.38,-0.18)$ & -0.17 & $(-0.55,0.20)$ & -0.45 & $(-0.84,-0.07)$ \\
\hline & Grodno & 1.58 & 1.93 & 2.08 & -0.34 & $(-0.46,-0.22)$ & -0.08 & $(-0.45,0.41)$ & -0.42 & $(-0.80,0.08)$ \\
\hline & Mogilev & 1.44 & 1.74 & 1.93 & -0.32 & $(-0.45,-0.23)$ & -0.20 & $(-0.59,0.14)$ & -0.52 & $(-0.94,-0.19)$ \\
\hline & Total & 1.43 & 1.76 & 1.96 & -0.29 & $(-0.35,-0.24)$ & -0.14 & $(-0.35,0.07)$ & -0.44 & $(-0.65,-0.22)$ \\
\hline \multirow[t]{12}{*}{ Belgium } & Brussels & 1.30 & 1.38 & 1.56 & -0.06 & $(-0.13,0.01)$ & -0.20 & $(-0.29,-0.12)$ & -0.27 & $(-0.35,-0.19)$ \\
\hline & Antwerp & 1.75 & 1.61 & 1.68 & 0.13 & $(0.09,0.17)$ & -0.06 & $(-0.11,-0.02)$ & 0.07 & $(0.02,0.12)$ \\
\hline & Brabant Walonne & 1.92 & 1.73 & 1.78 & 0.20 & $(0.13,0.27)$ & -0.06 & $(-0.14,0.02)$ & 0.14 & $(0.03,0.25)$ \\
\hline & Vlaams Brabant & 1.75 & 1.56 & 1.57 & 0.18 & $(0.13,0.23)$ & 0.00 & $(-0.06,0.05)$ & 0.18 & $(0.11,0.24)$ \\
\hline & West Flanders & 1.88 & 1.72 & 1.79 & 0.15 & $(0.10,0.20)$ & -0.07 & $(-0.12,-0.01)$ & 0.09 & $(0.02,0.15)$ \\
\hline & East Flanders & 1.72 & 1.59 & 1.66 & 0.14 & $(0.09,0.18)$ & -0.07 & $(-0.11,-0.02)$ & 0.07 & $(0.01,0.12)$ \\
\hline & Limburg & 1.73 & 1.60 & 1.66 & 0.12 & $(0.06,0.17)$ & -0.06 & $(-0.11,0.01)$ & 0.07 & $(0.00,0.14)$ \\
\hline & Liège & 1.74 & 1.71 & 1.91 & 0.02 & $(-0.03,0.07)$ & -0.20 & $(-0.25,-0.14)$ & -0.17 & $(-0.24,-0.11)$ \\
\hline & Namur & 1.89 & 1.81 & 2.00 & 0.08 & $(0.01,0.15)$ & -0.19 & $(-0.26,-0.12)$ & -0.11 & $(-0.20,-0.01)$ \\
\hline & Luxembourg & 2.03 & 1.98 & 2.18 & 0.03 & $(-0.08,0.13)$ & -0.18 & $(-0.28,-0.05)$ & -0.15 & $(-0.29,-0.01)$ \\
\hline & Hainaut & 1.69 & 1.71 & 1.98 & -0.02 & $(-0.07,0.03)$ & -0.27 & $(-0.33,-0.22)$ & -0.29 & $(-0.35,-0.23)$ \\
\hline & Total & 1.74 & 1.65 & 1.78 & 0.10 & $(0.08,0.12)$ & -0.11 & $(-0.13,-0.09)$ & -0.01 & $(-0.03,0.01)$ \\
\hline \multirow[t]{5}{*}{ Finland } & Helsinki-Uusimaa & 1.65 & 1.71 & 1.84 & -0.06 & $(-0.17,0.05)$ & -0.12 & $(-0.31,0.06)$ & -0.18 & $(-0.36,-0.01)$ \\
\hline & West Finland & 1.91 & 2.09 & 2.04 & -0.15 & $(-0.25,-0.01)$ & 0.05 & $(-0.13,0.25)$ & -0.09 & $(-0.26,0.13)$ \\
\hline & South Finland & 1.80 & 1.95 & 1.97 & -0.17 & $(-0.29,-0.07)$ & -0.03 & $(-0.24,0.11)$ & -0.20 & $(-0.42,-0.06)$ \\
\hline & North and East Finland & 2.00 & 2.25 & 2.14 & -0.26 & $(-0.39,-0.13)$ & 0.11 & $(-0.12,0.32)$ & -0.14 & $(-0.38,0.06)$ \\
\hline & Total & 1.81 & 1.99 & 1.97 & -0.15 & $(-0.21,-0.08)$ & -0.01 & $(-0.13,0.10)$ & -0.16 & $(-0.27,-0.05)$ \\
\hline \multirow[t]{9}{*}{ France } & Parisian region & 1.56 & 1.68 & 1.90 & -0.11 & $(-0.13,-0.10)$ & -0.22 & $(-0.24,-0.20)$ & -0.34 & $(-0.35,-0.32)$ \\
\hline & Central East France & 1.93 & 1.87 & 2.11 & 0.06 & $(0.05,0.08)$ & -0.24 & $(-0.26,-0.22)$ & -0.18 & $(-0.20,-0.15)$ \\
\hline & Mediterranean France & 1.65 & 1.77 & 1.98 & -0.12 & $(-0.14,-0.11)$ & -0.21 & $(-0.23,-0.19)$ & -0.33 & $(-0.35,-0.31)$ \\
\hline & South West France & 1.74 & 1.73 & 1.90 & 0.01 & $(-0.01,0.02)$ & -0.17 & $(-0.19,-0.15)$ & -0.16 & $(-0.19,-0.14)$ \\
\hline & West France & 1.98 & 2.06 & 2.24 & -0.08 & $(-0.10,-0.07)$ & -0.18 & $(-0.20,-0.16)$ & -0.26 & $(-0.29,-0.24)$ \\
\hline & Paris Basin & 1.82 & 1.91 & 2.15 & -0.09 & $(-0.10,-0.07)$ & -0.24 & $(-0.26,-0.22)$ & -0.33 & $(-0.35,-0.31)$ \\
\hline & East France & 1.72 & 1.89 & 2.09 & -0.17 & $(-0.19,-0.15)$ & -0.20 & $(-0.23,-0.18)$ & -0.37 & $(-0.40,-0.35)$ \\
\hline & North France & 1.80 & 2.12 & 2.47 & -0.33 & $(-0.35,-0.30)$ & -0.35 & $(-0.37,-0.32)$ & -0.67 & $(-0.70,-0.65)$ \\
\hline & Total & 1.76 & 1.87 & 2.10 & -0.09 & $(-0.10,-0.08)$ & -0.22 & $(-0.23,-0.21)$ & -0.31 & $(-0.32,-0.30)$ \\
\hline \multirow[t]{11}{*}{ Germany } & Hesse & 1.32 & 1.43 & 1.66 & -0.11 & $(-0.20,-0.03)$ & -0.25 & $(-0.40,-0.13)$ & -0.36 & $(-0.51,-0.25)$ \\
\hline & Bavaria & 1.45 & 1.60 & 1.65 & -0.15 & $(-0.22,-0.08)$ & -0.01 & $(-0.12,0.11)$ & -0.16 & $(-0.27,-0.03)$ \\
\hline & Baden-Wuerttemberg & 1.48 & 1.59 & 1.68 & -0.12 & $(-0.19,-0.04)$ & -0.10 & $(-0.22,0.01)$ & -0.21 & $(-0.34,-0.10)$ \\
\hline & Schleswig-Holstein and Hamburg & 1.25 & 1.39 & 1.63 & -0.15 & $(-0.25,-0.07)$ & -0.20 & $(-0.35,-0.04)$ & -0.36 & $(-0.50,-0.20)$ \\
\hline & North Rhine-Westphalia & 1.32 & 1.43 & 1.66 & -0.12 & $(-0.18,-0.06)$ & -0.24 & $(-0.33,-0.15)$ & -0.36 & $(-0.46,-0.27)$ \\
\hline & Lower Saxony and Bremen & 1.42 & 1.50 & 1.70 & -0.07 & $(-0.13,0.03)$ & -0.20 & $(-0.32,-0.09)$ & -0.27 & $(-0.38,-0.14)$ \\
\hline & Rhineland Palatinate and Saarland & 1.37 & 1.50 & 1.66 & -0.14 & $(-0.24,-0.07)$ & -0.19 & $(-0.33,-0.06)$ & -0.32 & $(-0.50,-0.21)$ \\
\hline & Berlin and Brandenburg & 1.33 & 1.41 & 1.68 & -0.08 & $(-0.15,0.02)$ & -0.25 & $(-0.41,-0.11)$ & -0.33 & $(-0.47,-0.18)$ \\
\hline & Saxony and Thuringia & 1.53 & 1.62 & 1.71 & -0.08 & $(-0.16,0.01)$ & -0.12 & $(-0.31,0.02)$ & -0.20 & $(-0.37,-0.06)$ \\
\hline & Meckl.-West. Pom. and Sax.-Anh. & 1.46 & 1.58 & 1.68 & -0.12 & $(-0.21,-0.03)$ & -0.09 & $(-0.22,0.09)$ & -0.20 & $(-0.33,-0.04)$ \\
\hline & Total & 1.40 & 1.51 & 1.67 & -0.11 & $(-0.15,-0.08)$ & -0.16 & $(-0.21,-0.11)$ & -0.27 & $(-0.33,-0.22)$ \\
\hline
\end{tabular}




\begin{tabular}{|c|c|c|c|c|c|c|c|c|c|c|}
\hline \multirow{2}{*}{$\begin{array}{l}\text { Country } \\
\text { Greece }\end{array}$} & \multirow{2}{*}{$\frac{\text { Region }}{\text { Attiki }}$} & \multirow{2}{*}{$\begin{array}{r}\text { High } \\
1.38\end{array}$} & \multirow{2}{*}{$\frac{\text { Med }}{1.50}$} & \multirow{2}{*}{$\frac{\text { Low }}{1.82}$} & \multicolumn{2}{|c|}{$\Delta$ High - Med $(95 \% \mathrm{Cl})$} & \multicolumn{2}{|c|}{$\Delta$ Med - Low $(95 \% \mathrm{Cl})$} & \multicolumn{2}{|c|}{$\Delta$ High - Low $(95 \% \mathrm{Cl}$} \\
\hline & & & & & -0.12 & $(-0.18,-0.06)$ & -0.32 & $(-0.40,-0.24)$ & -0.44 & $(-0.53,-0.36)$ \\
\hline & Notio Aigaio & 1.67 & 1.84 & 2.24 & -0.20 & $(-0.37,-0.10)$ & -0.40 & $(-0.57,-0.22)$ & -0.60 & $(-0.82,-0.44)$ \\
\hline & Dytiki Makedonia & 1.79 & 1.97 & 2.25 & -0.24 & $(-0.43,-0.10)$ & -0.23 & $(-0.41,0.00)$ & -0.47 & $(-0.67,-0.25)$ \\
\hline & Ionia Nisia & 1.53 & 1.67 & 2.06 & -0.14 & $(-0.27,-0.03)$ & -0.39 & $(-0.57,-0.21)$ & -0.53 & $(-0.72,-0.35)$ \\
\hline & Sterea Ellada & 1.62 & 1.78 & 2.14 & -0.17 & $(-0.31,-0.06)$ & -0.36 & $(-0.50,-0.20)$ & -0.53 & $(-0.69,-0.38)$ \\
\hline & Kriti & 1.73 & 1.91 & 2.36 & -0.18 & $(-0.32,-0.06)$ & -0.46 & $(-0.63,-0.30)$ & -0.64 & $(-0.82,-0.48)$ \\
\hline & Peloponnisos & 1.57 & 1.72 & 2.10 & -0.10 & $(-0.20,0.06)$ & -0.40 & $(-0.57,-0.25)$ & -0.50 & $(-0.66,-0.32)$ \\
\hline & Voreio Aigaio & 1.65 & 1.81 & 2.09 & -0.17 & $(-0.32,-0.03)$ & -0.24 & $(-0.41,0.00)$ & -0.41 & $(-0.58,-0.17)$ \\
\hline & Kentriki Makedonia & 1.63 & 1.78 & 2.02 & -0.15 & $(-0.25,-0.05)$ & -0.23 & $(-0.34,-0.12)$ & -0.39 & $(-0.50,-0.27)$ \\
\hline & Dytiki Ellada & 1.70 & 1.87 & 2.34 & -0.17 & $(-0.30,-0.04)$ & -0.48 & $(-0.64,-0.33)$ & -0.65 & $(-0.82,-0.50)$ \\
\hline & Anatoliki Makedonia, Thraki & 1.66 & 1.82 & 2.20 & -0.14 & $(-0.24,0.01)$ & -0.39 & $(-0.54,-0.24)$ & -0.52 & $(-0.67,-0.36)$ \\
\hline & Ipeiros & 1.69 & 1.85 & 2.14 & -0.16 & $(-0.30,-0.03)$ & -0.27 & $(-0.43,-0.07)$ & -0.44 & $(-0.60,-0.22)$ \\
\hline & Thessalia & 1.71 & 1.88 & 2.21 & -0.15 & $(-0.26,-0.01)$ & -0.34 & $(-0.48,-0.19)$ & -0.48 & $(-0.63,-0.32)$ \\
\hline & Total & 1.54 & 1.69 & 2.09 & -0.14 & $(-0.19,-0.10)$ & -0.33 & $(-0.38,-0.28)$ & -0.48 & $(-0.53,-0.43)$ \\
\hline \multirow[t]{8}{*}{ Hungary } & Central Hungary & 1.58 & 1.63 & 2.14 & -0.04 & $(-0.07,-0.02)$ & -0.51 & $(-0.56,-0.47)$ & -0.56 & $(-0.60,-0.51)$ \\
\hline & Western Transdanubia & 1.71 & 1.78 & 2.14 & -0.06 & $(-0.10,-0.01)$ & -0.36 & $(-0.42,-0.30)$ & -0.42 & $(-0.49,-0.35)$ \\
\hline & Central Transdanubia & 1.74 & 1.86 & 2.34 & -0.11 & $(-0.15,-0.07)$ & -0.48 & $(-0.54,-0.43)$ & -0.59 & $(-0.65,-0.53)$ \\
\hline & Southern Great Plain & 1.67 & 1.77 & 2.38 & -0.10 & $(-0.12,-0.05)$ & -0.61 & $(-0.67,-0.56)$ & -0.71 & $(-0.77,-0.64)$ \\
\hline & Southern Transdanubia & 1.72 & 1.84 & 2.35 & -0.13 & $(-0.17,-0.09)$ & -0.51 & $(-0.56,-0.45)$ & -0.63 & $(-0.69,-0.58)$ \\
\hline & Northern Great Plain & 1.73 & 1.90 & 2.65 & -0.17 & $(-0.21,-0.14)$ & -0.75 & $(-0.80,-0.71)$ & -0.92 & $(-0.98,-0.87)$ \\
\hline & Northern Hungary & 1.66 & 1.83 & 2.78 & -0.16 & $(-0.20,-0.12)$ & -0.95 & $(-1.00,-0.90)$ & -1.11 & $(-1.17,-1.05)$ \\
\hline & Total & 1.66 & 1.77 & 2.42 & -0.10 & $(-0.12,-0.09)$ & -0.59 & $(-0.61,-0.57)$ & -0.69 & $(-0.72,-0.67)$ \\
\hline \multirow[t]{3}{*}{ Ireland } & Southern and Eastern & 1.85 & 2.05 & 2.34 & -0.20 & $(-0.28,-0.11)$ & -0.30 & $(-0.40,-0.19)$ & -0.49 & $(-0.60,-0.39)$ \\
\hline & Border, Midland and Western & 1.95 & 2.23 & 2.48 & -0.28 & $(-0.43,-0.14)$ & -0.25 & $(-0.42,-0.08)$ & -0.53 & $(-0.70,-0.36)$ \\
\hline & Total & 1.88 & 2.10 & 2.38 & -0.22 & $(-0.29,-0.14)$ & -0.28 & $(-0.37,-0.19)$ & -0.50 & $(-0.59,-0.41)$ \\
\hline \multirow[t]{3}{*}{ Lithuania } & Vilnius & 1.37 & 1.54 & 1.58 & -0.16 & $(-0.22,-0.09)$ & -0.05 & $(-0.18,0.08)$ & -0.21 & $(-0.35,-0.07)$ \\
\hline & Rest of Lithuania & 1.63 & 1.95 & 2.11 & -0.31 & $(-0.34,-0.29)$ & -0.16 & $(-0.22,-0.10)$ & -0.47 & $(-0.54,-0.41)$ \\
\hline & Total & 1.56 & 1.90 & 2.06 & -0.29 & $(-0.31,-0.26)$ & -0.14 & $(-0.20,-0.08)$ & -0.43 & $(-0.49,-0.37)$ \\
\hline \multirow[t]{13}{*}{ Netherlands } & Groningen & 1.62 & 1.78 & 1.83 & -0.16 & $(-0.22,-0.11)$ & -0.04 & $(-0.10,0.03)$ & -0.20 & $(-0.28,-0.13)$ \\
\hline & Noord-Holland & 1.56 & 1.67 & 1.69 & -0.11 & $(-0.13,-0.08)$ & -0.03 & $(-0.06,0.01)$ & -0.13 & $(-0.17,-0.10)$ \\
\hline & Utrecht & 1.71 & 1.79 & 1.79 & -0.08 & $(-0.11,-0.04)$ & 0.00 & $(-0.05,0.05)$ & -0.07 & $(-0.13,-0.02)$ \\
\hline & Noord-Brabant & 1.79 & 1.81 & 1.69 & -0.02 & $(-0.05,0.01)$ & 0.12 & $(0.09,0.15)$ & 0.10 & $(0.07,0.14)$ \\
\hline & Zuid-Holland & 1.48 & 1.87 & 2.47 & -0.40 & $(-0.45,-0.35)$ & -0.59 & $(-0.64,-0.54)$ & -0.99 & $(-1.04,-0.93)$ \\
\hline & Gelderland & 1.79 & 1.89 & 1.88 & -0.11 & $(-0.14,-0.08)$ & 0.01 & $(-0.03,0.05)$ & -0.10 & $(-0.14,-0.06)$ \\
\hline & Overijssel & 1.88 & 1.99 & 2.03 & -0.10 & $(-0.15,-0.06)$ & -0.04 & $(-0.09,0.01)$ & -0.14 & $(-0.20,-0.08)$ \\
\hline & Limburg & 1.66 & 1.66 & 1.56 & 0.01 & $(-0.03,0.05)$ & 0.10 & $(0.06,0.14)$ & 0.11 & $(0.06,0.16)$ \\
\hline & Zeeland & 1.75 & 1.88 & 2.17 & -0.13 & $(-0.19,-0.06)$ & -0.28 & $(-0.37,-0.20)$ & -0.41 & $(-0.52,-0.31)$ \\
\hline & Flevoland & 1.83 & 1.91 & 2.18 & -0.08 & $(-0.15,0.00)$ & -0.27 & $(-0.36,-0.19)$ & -0.35 & $(-0.45,-0.25)$ \\
\hline & Friesland & 1.92 & 2.01 & 1.92 & -0.10 & $(-0.15,-0.05)$ & 0.10 & $(0.03,0.16)$ & 0.00 & $(-0.08,0.07)$ \\
\hline & Drenthe & 1.84 & 1.88 & 1.83 & -0.03 & $(-0.08,0.03)$ & 0.05 & $(-0.02,0.11)$ & 0.02 & $(-0.06,0.10)$ \\
\hline & Total & 1.71 & 1.82 & 1.89 & -0.10 & $(-0.11,-0.08)$ & -0.03 & $(-0.04,-0.01)$ & -0.12 & $(-0.14,-0.11)$ \\
\hline \multirow[t]{8}{*}{ Norway } & Oslo and Akershus & 1.72 & 1.69 & 1.67 & 0.03 & $(-0.03,0.09)$ & 0.01 & $(-0.07,0.09)$ & 0.05 & $(-0.03,0.12)$ \\
\hline & Agder and Rogaland & 2.21 & 2.25 & 2.28 & -0.04 & $(-0.11,0.04)$ & -0.04 & $(-0.13,0.05)$ & -0.08 & $(-0.18,0.02)$ \\
\hline & Western Norway & 2.21 & 2.29 & 2.33 & -0.08 & $(-0.16,-0.02)$ & -0.05 & $(-0.14,0.04)$ & -0.13 & $(-0.24,-0.04)$ \\
\hline & Trøndelag & 2.15 & 2.17 & 2.18 & -0.02 & $(-0.11,0.06)$ & 0.00 & $(-0.08,0.14)$ & -0.02 & $(-0.11,0.12)$ \\
\hline & Northern Norway & 2.13 & 2.20 & 2.24 & -0.07 & $(-0.15,0.01)$ & -0.06 & $(-0.19,0.03)$ & -0.13 & $(-0.26,-0.03)$ \\
\hline & South Eastern Norway & 1.99 & 1.97 & 1.97 & 0.03 & $(-0.03,0.10)$ & -0.02 & $(-0.10,0.06)$ & 0.01 & $(-0.07,0.10)$ \\
\hline & Hedmark and Oppland & 2.02 & 2.01 & 2.01 & 0.02 & $(-0.05,0.12)$ & 0.01 & $(-0.08,0.12)$ & 0.03 & $(-0.06,0.16)$ \\
\hline & Total & 1.99 & 2.04 & 2.05 & -0.01 & $(-0.04,0.02)$ & -0.02 & $(-0.06,0.03)$ & -0.03 & $(-0.07,0.02)$ \\
\hline
\end{tabular}


Appendix 7 continues

\begin{tabular}{|c|c|c|c|c|c|c|c|c|c|c|}
\hline \multirow{2}{*}{$\frac{\text { Country }}{\text { Romania }}$} & \multirow{2}{*}{$\begin{array}{l}\text { Region } \\
\text { Bucharest - IIfov }\end{array}$} & \multirow{2}{*}{$\begin{array}{r}\text { High } \\
1.01\end{array}$} & \multirow{2}{*}{$\frac{\text { Med }}{1.27}$} & \multirow{2}{*}{$\frac{\text { Low }}{1.78}$} & \multicolumn{2}{|c|}{$\Delta$ High - Med $(95 \% \mathrm{Cl})$} & \multicolumn{2}{|c|}{$\Delta$ Med - Low $(95 \% \mathrm{Cl})$} & \multicolumn{2}{|c|}{$\Delta$ High - Low $(95 \% \mathrm{Cl}$} \\
\hline & & & & & -0.27 & $(-0.32,-0.20)$ & -0.51 & $(-0.60,-0.41)$ & -0.77 & $(-0.87,-0.67)$ \\
\hline & West & 1.08 & 1.46 & 2.10 & -0.38 & $(-0.46,-0.31)$ & -0.64 & $(-0.73,-0.56)$ & -1.02 & $(-1.12,-0.93)$ \\
\hline & Center & 1.22 & 1.61 & 2.41 & -0.38 & $(-0.46,-0.29)$ & -0.80 & $(-0.91,-0.71)$ & -1.18 & $(-1.29,-1.08)$ \\
\hline & Northwest & 1.20 & 1.64 & 2.38 & -0.44 & $(-0.51,-0.36)$ & -0.74 & $(-0.82,-0.66)$ & -1.18 & $(-1.27,-1.08)$ \\
\hline & South - Muntenia & 1.15 & 1.55 & 2.15 & -0.40 & $(-0.46,-0.33)$ & -0.60 & $(-0.68,-0.52)$ & -1.00 & $(-1.08,-0.90)$ \\
\hline & South East & 1.12 & 1.50 & 2.23 & -0.38 & $(-0.45,-0.31)$ & -0.74 & $(-0.82,-0.66)$ & -1.12 & $(-1.21,-1.03)$ \\
\hline & South-West Oltenia & 1.13 & 1.60 & 2.21 & -0.46 & $(-0.54,-0.38)$ & -0.61 & $(-0.70,-0.52)$ & -1.07 & $(-1.17,-0.96)$ \\
\hline & Northeast & 1.18 & 1.82 & 2.61 & -0.65 & $(-0.72,-0.57)$ & -0.79 & $(-0.87,-0.70)$ & -1.43 & $(-1.53,-1.33)$ \\
\hline & Total & 1.12 & 1.57 & 2.28 & -0.42 & $(-0.45,-0.40)$ & -0.68 & $(-0.71,-0.65)$ & -1.10 & $(-1.14,-1.07)$ \\
\hline \multirow[t]{16}{*}{ Spain } & Madrid & 1.10 & 1.19 & 1.36 & -0.10 & $(-0.13,-0.06)$ & -0.17 & $(-0.24,-0.10)$ & -0.26 & $(-0.34,-0.19)$ \\
\hline & Basque Community & 1.35 & 1.42 & 1.50 & -0.06 & $(-0.08,-0.05)$ & -0.08 & $(-0.11,-0.05)$ & -0.14 & $(-0.17,-0.11)$ \\
\hline & Navarre & 1.35 & 1.51 & 1.66 & -0.16 & $(-0.18,-0.14)$ & -0.15 & $(-0.18,-0.12)$ & -0.31 & $(-0.35,-0.28)$ \\
\hline & Catalonia & 1.32 & 1.47 & 1.83 & -0.15 & $(-0.21,-0.09)$ & -0.37 & $(-0.47,-0.28)$ & -0.51 & $(-0.62,-0.42)$ \\
\hline & Aragon & 1.43 & 1.72 & 1.86 & -0.29 & $(-0.33,-0.25)$ & -0.14 & $(-0.19,-0.10)$ & -0.43 & $(-0.49,-0.38)$ \\
\hline & La Rioja & 1.44 & 1.65 & 1.89 & -0.21 & $(-0.23,-0.20)$ & -0.24 & $(-0.26,-0.22)$ & -0.45 & $(-0.47,-0.43)$ \\
\hline & Castile-Leon & 1.22 & 1.31 & 1.35 & -0.09 & $(-0.14,-0.05)$ & -0.04 & $(-0.11,0.04)$ & -0.13 & $(-0.21,-0.05)$ \\
\hline & Cantabria & 1.48 & 1.68 & 1.91 & -0.20 & $(-0.24,-0.16)$ & -0.23 & $(-0.28,-0.17)$ & -0.43 & $(-0.48,-0.37)$ \\
\hline & Principality of Asturias & 1.35 & 1.64 & 1.76 & -0.29 & $(-0.32,-0.26)$ & -0.12 & $(-0.16,-0.08)$ & -0.41 & $(-0.46,-0.37)$ \\
\hline & Galicia & 1.23 & 1.42 & 1.55 & -0.19 & $(-0.22,-0.17)$ & -0.13 & $(-0.17,-0.09)$ & -0.32 & $(-0.36,-0.28)$ \\
\hline & Valencian Community & 1.31 & 1.42 & 1.47 & -0.11 & $(-0.14,-0.08)$ & -0.05 & $(-0.11,0.01)$ & -0.16 & $(-0.23,-0.09)$ \\
\hline & Murcia & 1.21 & 1.38 & 1.43 & -0.16 & $(-0.18,-0.14)$ & -0.06 & $(-0.10,-0.01)$ & -0.22 & $(-0.26,-0.17)$ \\
\hline & Castille-La Mancha & 1.28 & 1.27 & 1.37 & 0.02 & $(-0.01,0.04)$ & -0.10 & $(-0.15,-0.05)$ & -0.08 & $(-0.13,-0.03)$ \\
\hline & Andalucia & 1.33 & 1.39 & 1.50 & -0.06 & $(-0.08,-0.05)$ & -0.11 & $(-0.15,-0.08)$ & -0.17 & $(-0.21,-0.14)$ \\
\hline & Extremadura & 1.37 & 1.43 & 1.62 & -0.06 & $(-0.10,-0.01)$ & -0.19 & $(-0.27,-0.11)$ & -0.25 & $(-0.33,-0.16)$ \\
\hline & Total & 1.34 & 1.48 & 1.71 & -0.14 & $(-0.14,-0.13)$ & -0.14 & $(-0.15,-0.13)$ & -0.28 & $(-0.29,-0.27)$ \\
\hline \multirow[t]{9}{*}{ Sweden } & Stockholm & 1.80 & 1.78 & 1.88 & 0.02 & $(-0.01,0.05)$ & -0.08 & $(-0.14,-0.02)$ & -0.06 & $(-0.12,0.00)$ \\
\hline & Upper Norrland & 2.00 & 2.03 & 2.11 & -0.03 & $(-0.08,0.00)$ & -0.06 & $(-0.13,0.04)$ & -0.10 & $(-0.16,-0.01)$ \\
\hline & West Sweden & 1.93 & 1.94 & 2.04 & -0.01 & $(-0.04,0.02)$ & -0.10 & $(-0.15,-0.05)$ & -0.11 & $(-0.16,-0.06)$ \\
\hline & Middle Norrland & 2.01 & 2.03 & 2.13 & -0.02 & $(-0.06,0.02)$ & -0.10 & $(-0.18,-0.03)$ & -0.12 & $(-0.20,-0.05)$ \\
\hline & East Middle Sweden & 1.98 & 1.99 & 2.11 & -0.01 & $(-0.04,0.03)$ & -0.12 & $(-0.18,-0.07)$ & -0.13 & $(-0.19,-0.08)$ \\
\hline & Småland and the islands & 2.05 & 2.08 & 2.16 & -0.03 & $(-0.08,0.01)$ & -0.07 & $(-0.14,0.02)$ & -0.10 & $(-0.17,-0.02)$ \\
\hline & South Sweden & 1.90 & 1.89 & 2.03 & 0.01 & $(-0.02,0.05)$ & -0.14 & $(-0.21,-0.08)$ & -0.13 & $(-0.20,-0.08)$ \\
\hline & North Sweden & 2.00 & 2.01 & 2.12 & -0.01 & $(-0.04,0.03)$ & -0.10 & $(-0.16,-0.03)$ & -0.11 & $(-0.17,-0.03)$ \\
\hline & Total & 1.93 & 1.94 & 2.04 & 0.00 & $(-0.02,0.01)$ & -0.10 & $(-0.13,-0.07)$ & -0.10 & $(-0.13,-0.08)$ \\
\hline
\end{tabular}

Note: Results for Austria, France, and Spain are based on a weighted sample. Sub-national regions within a country are ranked by the GDP (per capita) of the region, from highest to lowest. $95 \% \mathrm{Cl}=95$ percent credible interval. Meckl.-West. Pom. and Sax.-Anh. = Mecklenburg-Western Pomerania and Saxony-Anhalt. 


\section{Appendix 8}

Coefficients and $p$-values from linear models regressing differences in cohort fertility rates between educational groups and educational group-specific cohort fertility rates on logged GDP per capita: without and with country fixed effects in the sample of 15 European countries. Estimation is based on Empirical Bayesian cohort fertility rates.

\begin{tabular}{|c|c|c|c|c|c|c|c|c|c|c|c|c|}
\hline & \multicolumn{2}{|c|}{$\Delta$ High - Med } & \multicolumn{2}{|c|}{$\Delta$ Med - Low ${ }^{1}$} & \multicolumn{2}{|c|}{$\Delta$ High - Low } & \multicolumn{2}{|c|}{ High } & \multicolumn{2}{|c|}{ Medium } & \multicolumn{2}{|c|}{ Low } \\
\hline & $b$ & $\mathrm{P}>\mathrm{t}$ & $b$ & $\mathrm{P}>\mathrm{t}$ & $b$ & $\mathrm{P}>\mathrm{t}$ & $\mathrm{b}$ & $\mathrm{P}>\mathrm{t}$ & $\mathrm{b}$ & $\mathrm{P}>\mathrm{t}$ & $\mathrm{b}$ & $\mathrm{P}>\mathrm{t}$ \\
\hline \multicolumn{13}{|l|}{ All countries } \\
\hline without country $\mathrm{fe}^{2}$ & 0.174 & 0.000 & 0.244 & 0.000 & 0.418 & 0.000 & 0.153 & 0.008 & -0.021 & 0.670 & -0.265 & 0.000 \\
\hline with country fe & 0.066 & 0.023 & 0.069 & 0.114 & 0.134 & 0.031 & -0.251 & 0.000 & -0.317 & 0.000 & -0.385 & 0.000 \\
\hline \multicolumn{13}{|c|}{ Without Eastern and Central (Belarus, Hungary, Lithuania, Romania) } \\
\hline without country fe & 0.079 & 0.035 & 0.166 & 0.001 & 0.245 & 0.001 & 0.024 & 0.799 & -0.055 & 0.527 & -0.221 & 0.018 \\
\hline with country fe & -0.006 & 0.876 & -0.027 & 0.615 & -0.033 & 0.671 & -0.331 & 0.000 & -0.324 & 0.000 & -0.297 & 0.001 \\
\hline \multicolumn{13}{|c|}{ Without Northern (Finland, Norway, Sweden) } \\
\hline without country fe & 0.165 & 0.000 & 0.220 & 0.000 & 0.385 & 0.000 & 0.057 & 0.289 & -0.108 & 0.021 & -0.328 & 0.000 \\
\hline with country fe & 0.063 & 0.051 & 0.083 & 0.090 & 0.145 & 0.039 & -0.236 & 0.000 & -0.299 & 0.000 & -0.381 & 0.000 \\
\hline \multicolumn{13}{|c|}{ Without German-speaking and Southern (Austria, Germany, Spain, Greece) } \\
\hline without country fe & 0.174 & 0.000 & 0.244 & 0.000 & 0.418 & 0.000 & 0.153 & 0.008 & -0.021 & 0.670 & -0.265 & 0.000 \\
\hline with country fe & 0.066 & 0.023 & 0.069 & 0.114 & 0.134 & 0.031 & -0.251 & 0.000 & -0.317 & 0.000 & -0.385 & 0.000 \\
\hline \multicolumn{13}{|c|}{ Without Western (Belgium, France, Ireland, Nerherlands) } \\
\hline without country fe & 0.175 & 0.000 & 0.249 & 0.000 & 0.424 & 0.000 & 0.144 & 0.037 & -0.031 & 0.600 & -0.280 & 0.000 \\
\hline with country fe & 0.094 & 0.001 & 0.084 & 0.062 & 0.178 & 0.002 & -0.198 & 0.000 & -0.292 & 0.000 & -0.376 & 0.000 \\
\hline
\end{tabular}

${ }^{1}$ Med $=$ Medium $\quad{ }^{2} \mathrm{fe}=$ fixed effects

Coefficients and $p$-values from linear models regressing differences in cohort fertility rates between educational groups and educational group-specific cohort fertility rates on logged GDP per capita: without and with country fixed effects in the sample of 15 European countries. Estimation is based on observed cohort fertility rates.

\begin{tabular}{|c|c|c|c|c|c|c|c|c|c|c|c|c|}
\hline \multirow{3}{*}{ All countries } & \multicolumn{2}{|c|}{$\Delta$ High - Med ${ }^{1}$} & \multicolumn{2}{|c|}{$\Delta$ Med - Low ${ }^{1}$} & \multicolumn{2}{|c|}{$\Delta$ High - Low } & \multicolumn{2}{|c|}{ High } & \multicolumn{2}{|c|}{ Medium } & \multicolumn{2}{|c|}{ Low } \\
\hline & $\mathrm{b}$ & $\mathrm{P}>\mathrm{t}$ & $\mathrm{b}$ & $\mathrm{P}>\mathrm{t}$ & $\mathrm{b}$ & $\mathrm{P}>\mathrm{t}$ & $\mathrm{b}$ & $\mathrm{P}>\mathrm{t}$ & $\mathrm{b}$ & $\mathrm{P}>\mathrm{t}$ & $\mathrm{b}$ & $\mathrm{P}>\mathrm{t}$ \\
\hline & \\
\hline without country fe ${ }^{2}$ & 0.177 & 0.000 & 0.229 & 0.000 & 0.413 & 0.000 & 0.149 & 0.009 & -0.029 & 0.563 & -0.258 & 0.000 \\
\hline with country fe & 0.077 & 0.023 & 0.109 & 0.035 & 0.184 & 0.008 & -0.256 & 0.000 & -0.333 & 0.000 & -0.442 & 0.000 \\
\hline \multicolumn{13}{|c|}{ Without Eastern and Central (Belarus, Hungary, Lithuania, Romania) } \\
\hline without country fe & 0.095 & 0.018 & 0.134 & 0.006 & 0.228 & 0.002 & 0.010 & 0.917 & -0.086 & 0.325 & -0.220 & 0.020 \\
\hline with country fe & -0.006 & 0.888 & -0.025 & 0.665 & -0.031 & 0.698 & -0.350 & 0.000 & -0.344 & 0.000 & -0.319 & 0.000 \\
\hline \multicolumn{13}{|c|}{ Without Northern (Finland, Norway, Sweden) } \\
\hline without country fe & 0.166 & 0.000 & 0.210 & 0.000 & 0.384 & 0.000 & 0.053 & 0.323 & -0.113 & 0.016 & -0.323 & 0.000 \\
\hline with country fe & 0.074 & 0.048 & 0.127 & 0.029 & 0.198 & 0.011 & -0.241 & 0.000 & -0.316 & 0.000 & -0.442 & 0.000 \\
\hline \multicolumn{13}{|c|}{ Without German-speaking and Southern (Austria, Germany, Spain, Greece) } \\
\hline without country fe & 0.177 & 0.000 & 0.229 & 0.000 & 0.413 & 0.000 & 0.149 & 0.009 & -0.029 & 0.563 & -0.258 & 0.000 \\
\hline with country fe & 0.077 & 0.023 & 0.109 & 0.035 & 0.184 & 0.008 & -0.256 & 0.000 & -0.333 & 0.000 & -0.442 & 0.000 \\
\hline \multicolumn{13}{|c|}{ Without Western (Belgium, France, Ireland, Nerherlands) } \\
\hline without country fe & 0.179 & 0.000 & 0.242 & 0.000 & 0.428 & 0.000 & 0.143 & 0.037 & -0.037 & 0.539 & -0.278 & 0.000 \\
\hline with country fe & 0.103 & 0.004 & 0.151 & 0.010 & 0.251 & 0.000 & -0.203 & 0.000 & -0.306 & 0.000 & -0.458 & 0.000 \\
\hline
\end{tabular}

\footnotetext{
${ }^{1}$ Med $=$ Medium

${ }^{2}$ fe $=$ fixed effects
} 
Appendix 9 The difference in cohort fertility rate between high- and medium-educated women according to the GDP per capita level of the region of 15 European countries. Regression lines are fitted for the global trend without (black dashed line) and with (blue dashed line) country fixed effects, and for the within-country trends for each country separately (solid lines). Estimation is based on observed cohort fertility rates.

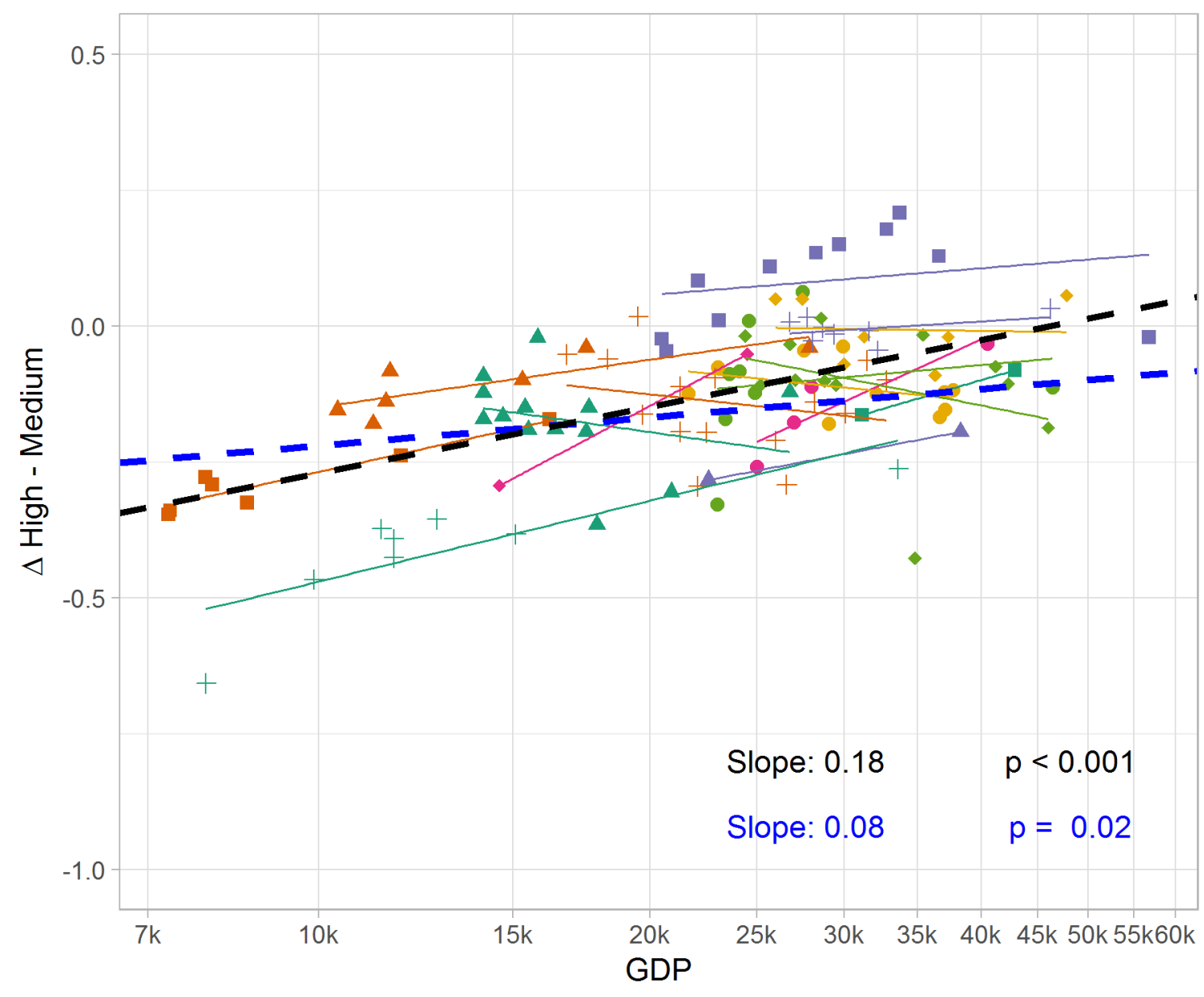

$\rightarrow$ Austria $\rightarrow$ Finland $\leftarrow$ Greece $\rightarrow$ Lithuania + Romania
$\rightarrow$ Belarus $\rightarrow$ France $\leftarrow$ Hungary $\rightarrow$ Netherlands + Spain
$\rightarrow-$ Belgium $\rightarrow$ Germany $\leftarrow$ Ireland $\rightarrow$ Norway + Sweden


Appendix 10 The difference in cohort fertility rate between medium- and low-educated women according to the GDP per capita level of the region of 15 European countries. Regression lines are fitted for the global trend without (black dashed line) and with (blue dashed line) country fixed effects, and for the within-country trends for each country separately (solid lines). Estimation is based on observed cohort fertility rates.

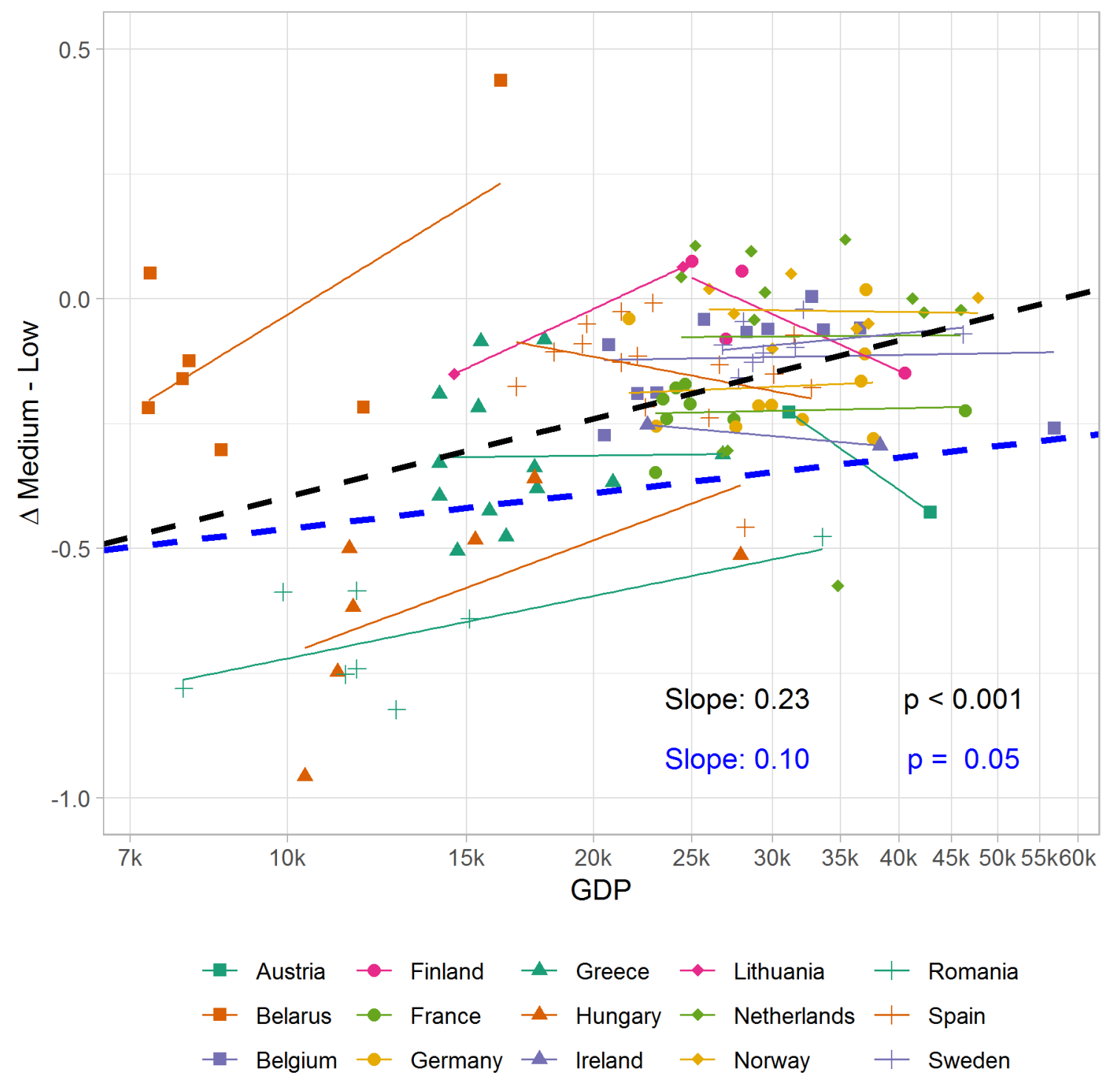


Appendix 11 The difference in cohort fertility rate between high- and low-educated women according to the GDP per capita level of the region of 15 European countries. Regression lines are fitted for the global trend without (black dashed line) and with (blue dashed line) country fixed effects, and for the within-country trends for each country separately (solid lines). Estimation is based on observed cohort fertility rates.

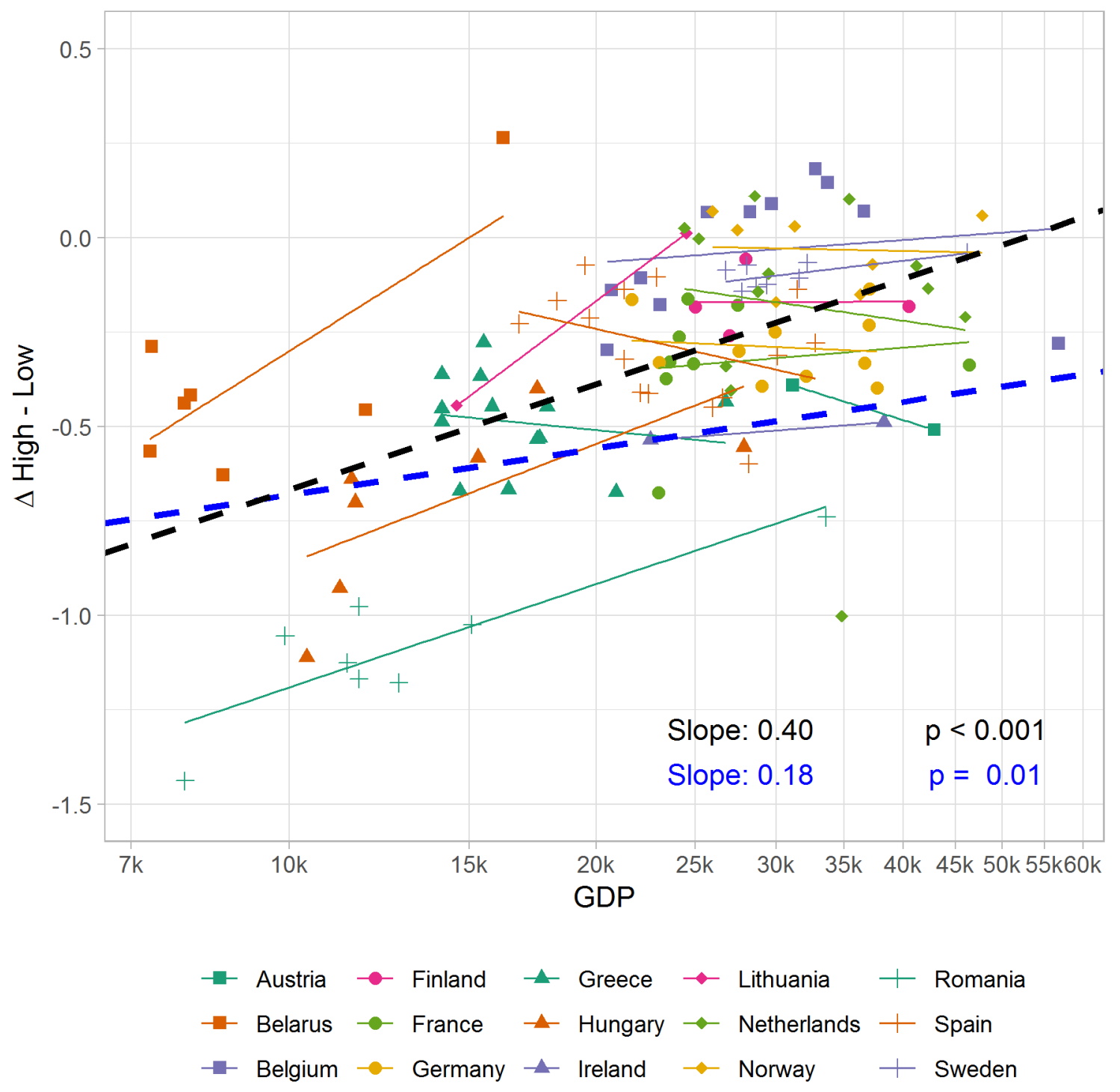

